\title{
Dance movement therapy for depression (Review)
}

\author{
Meekums B, Karkou V, Nelson EA
}

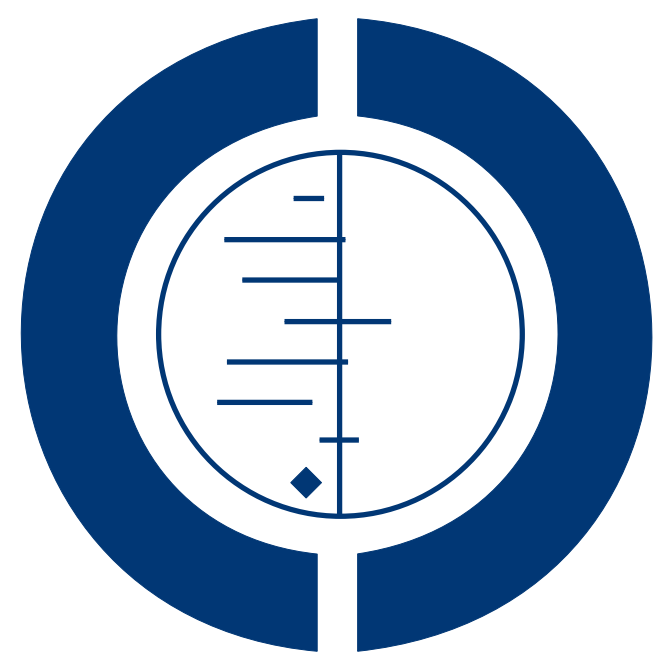

\section{THE COCHRANE COLLABORATION $^{\circledR}$}

This is a reprint of a Cochrane review, prepared and maintained by The Cochrane Collaboration and published in The Cochrane Library 2015, Issue 2

http://www.thecochranelibrary.com

\section{WILEY}


TABLE OF CONTENTS

HEADER . . . . . . . . . . . . . . . . . . . . . . . . . . . . . . . . . . 1

ABSTRACT . . . . . . . . . . . . . . . . . . . . . . . . . . . . . . . . . . . . . . .

PLAIN LANGUAGE SUMMARY . . . . . . . . . . . . . . . . . . . . . . . . . . . . . . . . . . . .

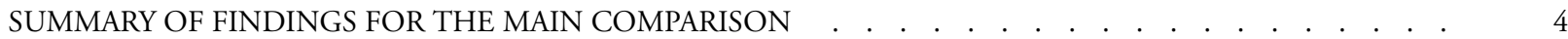

BACKGROUND . . . . . . . . . . . . . . . . . . . . . . . . . . . . . . . . . . . . . . . . . . . . . 7

OBJECTIVES . . . . . . . . . . . . . . . . . . . . . . . . . . . . . . . . . . . . . . . . . . . . .

METHODS . . . . . . . . . . . . . . . . . . . . . . . . . . . . . . . . . . . . . .

RESULTS . . . . . . . . . . . . . . . . . . . . . . . . . . . . . . . . . . . . . . 16

Figure 1. . . . . . . . . . . . . . . . . . . . . . . . . . . . . . . . . . . . 17

Figure 2. . . . . . . . . . . . . . . . . . . . . . . . . . . . . . . . . . . . . . 20

Figure 3. . . . . . . . . . . . . . . . . . . . . . . . . . . . . . . . . . 21

Figure $4 . \quad$. . . . . . . . . . . . . . . . . . . . . . . . . . . . . . . . . . . . . $\quad 23$

Figure 5. . . . . . . . . . . . . . . . . . . . . . . . . . . . . . . . . . . . . . 425

DISCUSSION . . . . . . . . . . . . . . . . . . . . . . . . . . . . . . . . . . . . 25

AUTHORS' CONCLUSIONS . . . . . . . . . . . . . . . . . . . . . . . . . . . . . . . . 28

ACKNOWLEDGEMENTS . . . . . . . . . . . . . . . . . . . . . . . . . . . . . . . . . 29

REFERENCES . . . . . . . . . . . . . . . . . . . . . . . . . . . . . . . . . . . . . . 29

CHARACTERISTICS OF STUDIES . . . . . . . . . . . . . . . . . . . . . . . . . . . . . . . 35

DATA AND ANALYSES . . . . . . . . . . . . . . . . . . . . . . . . . . . . . . . . . . . . . . . . . . . . . . . . 46

Analysis 1.1. Comparison 1 DMT vs standard care or waiting list control, Outcome 1 Depression score. . . . . . . 46

Analysis 1.2. Comparison 1 DMT vs standard care or waiting list control, Outcome 2 Depression score sub-group analysis children vs adults. . . . . . . . . . . . . . . . . . . . . . . . . . . . . . . . . 47

Analysis 1.3. Comparison 1 DMT vs standard care or waiting list control, Outcome 3 Drop-outs. . . . . . . . . 48

Analysis 1.4. Comparison 1 DMT vs standard care or waiting list control, Outcome 4 Social and occupational functioning. . . . . . . . . . . . . . . . . . . . . . . . . . . . . . . . . . . 48

Analysis 1.5. Comparison 1 DMT vs standard care or waiting list control, Outcome 5 Quality of life. . . . . . . 49

Analysis 1.6. Comparison 1 DMT vs standard care or waiting list control, Outcome 6 Self-esteem. . . . . . . . . 49

APPENDICES . . . . . . . . . . . . . . . . . . . . . . . . . . . . . . . . . . . . . . . . . . . . . . . 49

CONTRIBUTIONS OF AUTHORS . . . . . . . . . . . . . . . . . . . . . . . . . . . . . . . . . . . . . . . . . . . .

DECLARATIONS OF INTEREST . . . . . . . . . . . . . . . . . . . . . . . . . . . . . . . 53

SOURCES OF SUPPORT . . . . . . . . . . . . . . . . . . . . . . . . . . . . . . . . . . . . . . . . . . . . . . .

DIFFERENCES BETWEEN PROTOCOL AND REVIEW . . . . . . . . . . . . . . . . . . . . . . . . . . 54

INDEX TERMS . . . . . . . . . . . . . . . . . . . . . . . . . . . . . . . . . . . . . . . . . . . . . . $\quad 54$

Dance movement therapy for depression (Review)

Copyright $\odot 2015$ The Cochrane Collaboration. Published by John Wiley \& Sons, Ltd. 


\title{
[Intervention Review] \\ Dance movement therapy for depression
}

\author{
Bonnie Meekums $^{1}$, Vicky Karkou ${ }^{2}$, E Andrea Nelson ${ }^{1}$ \\ ${ }^{1}$ School of Healthcare, University of Leeds, Leeds, UK. ${ }^{2}$ Faculty of Arts and Sciences, Edge Hill University, Ormskirk, UK \\ Contact address: Bonnie Meekums, School of Healthcare, University of Leeds, Baines Wing, Leeds, West Yorkshire, LS2 9JT, UK. \\ B.Meekums@leeds.ac.uk.
}

Editorial group: Cochrane Depression, Anxiety and Neurosis Group.

Publication status and date: New, published in Issue 2, 2015.

Review content assessed as up-to-date: 2 October 2014.

Citation: Meekums B, Karkou V, Nelson EA. Dance movement therapy for depression. Cochrane Database of Systematic Reviews 2015, Issue 2. Art. No.: CD009895. DOI: 10.1002/14651858.CD009895.pub2.

Copyright (C) 2015 The Cochrane Collaboration. Published by John Wiley \& Sons, Ltd.

\begin{abstract}
A B S T R A C T
Background

Depression is a debilitating condition affecting more than 350 million people worldwide (WHO 2012) with a limited number of evidence-based treatments. Drug treatments may be inappropriate due to side effects and cost, and not everyone can use talking therapies. There is a need for evidence-based treatments that can be applied across cultures and with people who find it difficult to verbally articulate thoughts and feelings. Dance movement therapy (DMT) is used with people from a range of cultural and intellectual backgrounds, but effectiveness remains unclear.
\end{abstract}

\section{Objectives}

To examine the effects of DMT for depression with or without standard care, compared to no treatment or standard care alone, psychological therapies, drug treatment, or other physical interventions. Also, to compare the effectiveness of different DMT approaches.

\section{Search methods}

The Cochrane Depression, Anxiety and Neurosis Review Group's Specialised Register (CCDANCTR-Studies and CCDANCTRReferences) and CINAHL were searched (to 2 Oct 2014) together with the World Health Organization's International Clinical Trials Registry Platform (WHO ICTRP) and ClinicalTrials.gov. The review authors also searched the Allied and Complementary Medicine Database (AMED), the Education Resources Information Center (ERIC) and Dissertation Abstracts (to August 2013), handsearched bibliographies, contacted professional associations, educational programmes and dance therapy experts worldwide.

\section{Selection criteria}

Inclusion criteria were: randomised controlled trials (RCTs) studying outcomes for people of any age with depression as defined by the trialist, with at least one group being DMT. DMT was defined as: participatory dance movement with clear psychotherapeutic intent, facilitated by an individual with a level of training that could be reasonably expected within the country in which the trial was conducted. For example, in the USA this would either be a trainee, or qualified and credentialed by the American Dance Therapy Association (ADTA). In the UK, the therapist would either be in training with, or accredited by, the Association for Dance Movement Psychotherapy (ADMP, UK). Similar professional bodies exist in Europe, but in some countries (e.g. China) where the profession is in development, a lower level of qualification would mirror the situation some decades previously in the USA or UK. Hence, the review authors accepted a relevant professional qualification (e.g. nursing or psychodynamic therapies) plus a clear description of the treatment that would indicate its adherence to published guidelines including Levy 1992, ADMP UK 2015, Meekums 2002, and Karkou 2006.

Dance movement therapy for depression (Review)

Copyright $\odot 2015$ The Cochrane Collaboration. Published by John Wiley \& Sons, Ltd. 


\section{Data collection and analysis}

Study methodological quality was evaluated and data were extracted independently by the first two review authors using a data extraction form, the third author acting as an arbitrator.

\section{Main results}

Three studies totalling 147 participants (107 adults and 40 adolescents) met the inclusion criteria. Seventy-four participants took part in DMT treatment, while 73 comprised the control groups. Two studies included male and female adults with depression. One of these studies included outpatient participants; the other study was conducted with inpatients at an urban hospital. The third study reported findings with female adolescents in a middle-school setting. All included studies collected continuous data using two different depression measures: the clinician-completed Hamilton Depression Rating Scale (HAM-D); and the Symptom Checklist-90-R (SCL90-R) (self-rating scale).

Statistical heterogeneity was identified between the three studies. There was no reliable effect of DMT on depression (SMD -0.67 95\% CI -1.40 to 0.05 ; very low quality evidence). A planned subgroup analysis indicated a positive effect in adults, across two studies, 107 participants, but this failed to meet clinical significance (SMD -7.33 95\% CI -9.92 to -4.73).

One adult study reported drop-out rates, found to be non-significant with an odds ratio of 1.82 [95\% CI 0.35 to 9.45 ]; low quality evidence. One study measured social functioning, demonstrating a large positive effect (MD -6.80 95\% CI -11.44 to -2.16; very low quality evidence), but this result was imprecise. One study showed no effect in either direction for quality of life (0.30 95\% CI - 0.60 to 1.20 ; low quality evidence) or self esteem (1.70 95\% CI -2.36 to 5.76 ; low quality evidence).

\section{Authors' conclusions}

The low-quality evidence from three small trials with 147 participants does not allow any firm conclusions to be drawn regarding the effectiveness of DMT for depression. Larger trials of high methodological quality are needed to assess DMT for depression, with economic analyses and acceptability measures and for all age groups.

\section{PLAIN LANGUAGE SUMMARY}

\section{Is dance movement therapy an effective treatment for depression? A review of the evidence}

\section{Why is this review important?}

Depression affects 350 million people worldwide, impacting on quality of life, work, relationships and physical health. Medication and talking therapies are not always suitable or available. Dance movement therapy (DMT) uses bodily movements to explore and express emotions with groups or individuals. This is the first review of the effectiveness of DMT for depression and will add to the evidence base regarding depression treatments.

\section{Who might be interested in this review?}

People affected by depression.

General practitioners.

Mental health professionals.

Psychological therapists.

\section{What questions does this review aim to answer?}

Is DMT more effective than no treatment or standard care?

Is DMT more effective than talking therapies?

Is DMT more effective than medication?

Is DMT more effective than physical treatments such as dance or exercise?

How effective are different types of DMT?

Which studies were included in the review?

Dance movement therapy for depression (Review)

Copyright $\odot 2015$ The Cochrane Collaboration. Published by John Wiley \& Sons, Ltd. 
Databases were searched for all published and unpublished randomised controlled studies of DMT for depression up to October 2014, with participants of any age, gender or ethnicity. Three studies (147 participants) met inclusion criteria: two of adults (men and women); and one of adolescents (females only).

\section{What does the evidence from the review tell us?}

Due to the low number of studies and low quality of evidence, it was not possible to draw firm conclusions about the effectiveness of DMT for depression. It was not possible to compare DMT with medication, talking therapies, physical treatments or to compare types of DMT due to lack of available evidence. Key findings were:

Overall, there is no evidence for or against DMT as a treatment for depression. There is some evidence to suggest DMT is more effective than standard care for adults, but this was not clinically significant. DMT is no more effective than standard care for young people.

Evidence from just one study of low methodological quality suggested that drop-out rates from the DMT group were not significant, and there is no reliable effect in either direction for quality of life or self esteem. A large positive effect was observed for social functioning, but since this was from one study of low methodological quality the result is imprecise.

\section{What should happen next?}

Future studies should be of high methodological quality, comparing DMT with other treatments for depression, and include economic analyses. 
SUMMARY OF FINDINGSFOR THE MAINCOMPARISON [Explanation]

DMT compared to standard care or waiting list control for depression

Patient or population: patients with depression

Settings: hospital, school, community mental health services

Intervention: Dance movement therapy

Comparison: standard care or waiting list control

\begin{tabular}{|c|c|c|c|c|c|c|}
\hline \multirow[t]{3}{*}{ Outcomes } & \multicolumn{2}{|c|}{ Illustrative comparative risks* $(95 \% \mathrm{CI})$} & \multirow{3}{*}{$\begin{array}{l}\text { Relative effect } \\
(95 \% \mathrm{CI})\end{array}$} & \multirow{3}{*}{$\begin{array}{l}\text { No of Participants } \\
\text { (studies) }\end{array}$} & \multirow{3}{*}{$\begin{array}{l}\text { Quality of the evidence } \\
\text { (GRADE) }\end{array}$} & \multirow[t]{3}{*}{ Comments } \\
\hline & Assumed risk & Corresponding risk & & & & \\
\hline & $\begin{array}{l}\text { Standard care or waiting } \\
\text { list control }\end{array}$ & DMT & & & & \\
\hline $\begin{array}{l}\text { Depression score } \\
\text { SCL-90- } \\
\text { R depression sub-scale } \\
\text { (13 items); HAM-D. Scale } \\
\text { from: } 0 \text { to } 84 \text { (HAM-D) or } \\
52 \text { (SCL-90-R depression } \\
\text { sub-scale) }\end{array}$ & $\begin{array}{l}\text { For those (adult) studies } \\
\text { using the HAM-D scale, } \\
\text { the control group was } \\
\text { standard care, though for } \\
\text { one of these two studies } \\
\text { (Röhricht 2013) this was } \\
\text { also a waiting list group } \\
\text { for the intervention. For } \\
\text { the adolescent study us- } \\
\text { ing the SCL-90-R depres- } \\
\text { sion subscale, a waiting } \\
\text { list control was used }\end{array}$ & $\begin{array}{l}\text { The mean depression } \\
\text { score in the intervention } \\
\text { groups was } \\
0.67 \text { standard deviations } \\
\text { lower } \\
\text { (1.4 lower to } 0.05 \text { higher) }\end{array}$ & & $\begin{array}{l}147 \\
\text { (3 studies) }\end{array}$ & $\begin{array}{l}\oplus \bigcirc \bigcirc \bigcirc \\
\text { very low } 1,2,3\end{array}$ & $\begin{array}{l}\text { SMD -0.67 (-1.4 to } 0.05) \\
\text {, with a lower score in- } \\
\text { dicating less severe de- } \\
\text { pression } \\
\text { Using Cohen's rule of } \\
\text { thumb, SMD -0.67 is con- } \\
\text { sidered a medium effect. } \\
\text { However, the confidence } \\
\text { interval crosses the line } \\
\text { of no effect and into } \\
\text { the possibility of a very } \\
\text { small negative effect. The } \\
\text { proportion of information } \\
\text { from studies at high risk } \\
\text { of bias is sufficient to af- } \\
\text { fect the interpretation of } \\
\text { results. It is not possible, } \\
\text { therefore, to state with } \\
\text { confidence that DMT has } \\
\text { an effect in either direc- } \\
\text { tion }\end{array}$ \\
\hline
\end{tabular}




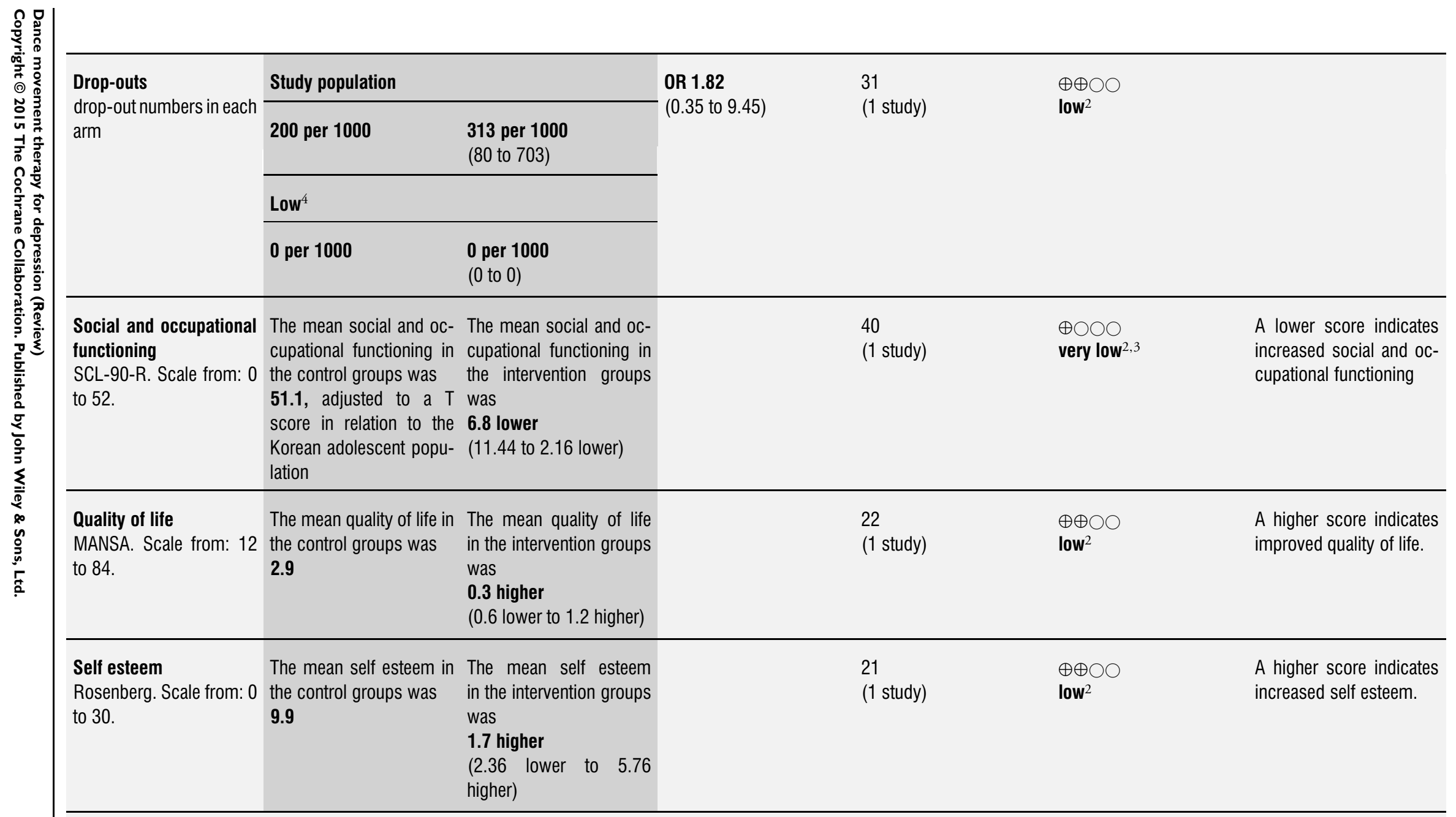

*The basis for the assumed risk (e.g. the median control group risk across studies) is provided in footnotes. The corresponding risk (and its $95 \%$ confidence interval) is based on the assumed risk in the comparison group and the relative effect of the intervention (and its $95 \% \mathrm{Cl}$ ).

Cl: Confidence interval; OR: Odds ratio; 
GRADE Working Group grades of evidence

High quality: Further research is very unlikely to change our confidence in the estimate of effect.

Moderate quality: Further research is likely to have an important impact on our confidence in the estimate of effect and may change the estimate.

Low quality: Further research is very likely to have an important impact on our confidence in the estimate of effect and is likely to change the estimate.

Very low quality: We are very uncertain about the estimate.

1 The quality of evidence for the depression score was downgraded two points because of heterogeneity across studies. This may be due either to age of participants, outcome measure used, blinding, the intervention, or some combination of these factors but the exact cause could not be established. However, the one study of adolescents is the lowest methodological quality of all three studies in this review, presenting a high risk of bias which is likely to affect results. This also used a different measure from the other two studies. One of the adult studies blinded allocation and assessment, but the other does not report. It is not possible to blind participants or therapist for this form of treatment, though clearly there is heterogeneity in the rigour employed with respect to blinding. One (adult, Chinese) study used a therapist of low training level; whilst this is consistent with the situation in that country regarding the development of professional practice standards, it may represent heterogeneity in the treatment intervention.

2 The quality of evidence on all measures was downgraded by two points because of imprecision caused by a low sample size.

3 The quality of evidence for both the depression and social/occupational functioning outcomes was downgraded by two points because both of these included a study which used the depression sub-scale of the SCL-90-R. This is not deemed to be a reliable measure, due to the fact that it relies on self-report.

4 The attrition risk due to reported drop-out rate is deemed to be low. Only one study (Röhricht 2013) reported any drop-outs, and although drop-out rates were approximately $11 \%$ higher in the DMT group than in the control, the odds ratio is calculated as 1.82 [0.35, 9.45], which is not significant. 


\section{B A C K G R O U N D}

\section{Description of the condition}

Depression is characterised by low mood, a loss of interest or pleasure in most activities, sleep disturbances (either lack of sleep or oversleeping), changes in appetite or unintentional changes of weight (up or down), decreased energy, either slowed or agitated movement, decreased concentration and, in some cases, feelings of guilt, worthlessness and thoughts of suicide (APA 2000). The diagnosis of major depression requires five or more of these symptoms, including depressed mood or a loss of interest or pleasure in most activities, which have been present during the same two-week period and cause significant distress or impairment of functioning (Williams 2002). Depression is a prevalent and growing condition; the World Health Organization (WHO 2010a) reported in 2010 that it affected about 121 million people worldwide, and by 2012 this figure had grown to in excess of 350 million (WHO 2012). In the UK, $6 \%$ of the population meet the criteria for major depressive disorder or dysthymia (chronic depression which is less severe than major depression) at any time, with $20 \%$ of major depressive disorders persisting more than two years, 30\% relapsing within three months of recovery and $50 \%$ within two years (Scott 2003). Depression thus represents a significant burden to families and to society. It has a negative impact on quality of life and can lead to suicide (Scott 2003). Depression often remains undiagnosed, which suggests that the real scale of the problem is probably much larger.

\section{Description of the intervention}

Dance movement therapy (DMT) is an arts therapy discipline which has reported evidence of effectiveness. For example, a metaanalysis completed by Ritter 1996 and recalculated by Cruz 1998 provides evidence for a mild to moderate effect size of DMT for a wide range of different client groups and for an array of symptoms including reduction of symptoms of anxiety and depression. More recently, an updated meta-analysis conducted by Koch 2014 has demonstrated that DMT has a moderate effect for a range of disorders, including depression. They included controlled as well as randomised controlled trials in their analysis, and trials of both dance and DMT. As DMT combines the benefits of mild physical activity and specifically dance with psychological therapies, it may open up the options within non-pharmaceutical therapy to people with depression who do not feel able or do not wish to focus exclusively on talking about their problems, or who prefer nonmedical approaches to treatment as identified in the 2010 NICE guideline (NICE 2010).

DMT is also known as dance therapy, movement therapy, dance movement psychotherapy, movement psychotherapy, dancel movement therapy and dance-movement therapy. One of the available professional definitions is as follows:

"the psychotherapeutic use of movement and dance through which a person can engage creatively in a process to further their emotional, cognitive, physical and social integration" (Association for Dance Movement Psychotherapy UK 1997, cited in Meekums 2002, p4).

DMT is thus a form of psychotherapy, which uses as its basis the creative movement process. The process has been described by Meekums 2002 as involving two key components: the movement metaphor as the central tool; and a creative change process within which this tool is used. A movement metaphor is "a symbol encapsulated in either a movement or posture" (Meekums 2002). The creative change process occurs within the context of a psychotherapeutic relationship and is conceptualised by Meekums as incorporating four key stages: preparation, incubation, illumination, and verification. These stages may be repeated in cyclical fashion. In addition Karkou 2006 argues that in DMT, dance is considered widely to include breathing, rhythm, pedestrian movement or gesturing and posturing, with a particular emphasis on imagery, symbolism and metaphors. The therapy tends to focus on nonverbal communication (with some verbal processing of issues and insights), while support is offered for the development of therapeutic relationships through movement and dance.

DMT is used with people from a wide range of cultural and intellectual backgrounds. The settings in which DMT is practised include: health services, schools, social services, voluntary organisations, and prisons. The format can include individual (one-toone) or group work.

DMT was originally developed in the 1940 s and 1950 s, in the USA by notable pioneers including Marian Chace (Levy 1992). Chace was an American dancer who developed methods still in widespread use today. Aspects of practice developed by her include an emphasis on the development of a therapeutic relationship through the empathic reflection of expressive movement qualities ('mirroring'), and supporting group social cohesion through rhythmic group synchrony. In the UK, a 'first wave' of DMT was developing around the same time, independently of American developments, but was superseded by a second, more psychotherapeutic approach which developed from the 1970s onwards (Meekums 2008). Meekums 2008 suggests that what marks out contemporary DMT practice is the emphasis on it as a form of psychotherapy. For many therapists, theories relating to psychoanalytic and psychodynamic principles are used to guide practice (Karkou 2006). For example, the practice of 'Authentic Movement' (Whitehouse 1979) is associated with Jungian psychology. For others, humanistic, developmental, behavioural or eclectic and integrative models are valued (Karkou 2006). Meekums 1991, for example, in her work with mothers and young children used a behaviourist approach combined with attachment theory. More recently, Meekums 2002 has suggested an integrative framework based on the symbolic power of the 'movement metaphor', which 
transcends such theoretical divisions.

DMT has been posited as an appropriate intervention for patients with a range of diagnoses and presenting problems, including those for whom words may be difficult either because of cognitive impairment or because the emotions being explored and expressed are too painful, pre-verbal in their origin, or too complex to readily express in words. Session lengths vary from 30 to 90 minutes and often take place on a weekly basis, at the same place and time to assist emotional security. Interventions may last from a few weeks to several months depending on client needs and the treatment context.

\section{How the intervention might work}

As a form of psychological therapy, DMT is very likely to work primarily because of non-specific factors, notably the therapeutic relationship which has been shown across many forms of therapy to be a key determinant of outcome. More specifically, Norcross 2011 identifies strong evidence for the importance of the therapeutic alliance, empathy, and for group therapy cohesion in psychological therapies. Based on this finding, some of the specific effects of DMT can be attributed to the use of non-verbal communication and kinaesthetic (embodied) empathy in particular (Brooks 1989; Berrol 2006; Meekums 2012). Dance movement therapists use close attention to their own embodied responses, together with 'mirroring' of expressive movement on occasions, in order to attempt understanding of their clients' feelings and experiences and communicate a level of empathic understanding. Recent research in mirroring argues that when this technique is used within DMT it improves social competence, body-awareness, self-other distinction and well-being for people with autism, and improves self experience, empathy and well-being in people with schizophrenia (Koch 2012, Koch submitted). The degree to which these effects are transferable to people with depression remains unclear. One possibility is that mirroring might lead to a reduction in depression due to reduced social withdrawal, but this proposition awaits testing.

Some DMT literature (for example Meekums 2002; Berrol 2006) discusses a possible link with so-called 'mirror neurons' (Rizzolatti 1996; Gazzola 2006). Mirror neurons are neurons that fire when individuals watch someone else performing an action or expressing emotion. The nature of the impulse mimics that which would occur, were the observer carrying out the observed action experiencing the emotional state. This occurs, provided that the observed state is broadly within the prior experience of the observer. The suggestion is made that empathic engagement associated with active 'mirroring' is in part mediated through the activation of mirror neurons. However, while echoing of movement qualities (that is, reproducing expressive qualities, shortly after the patient or client has done so) has long been associated with empathy and positive feelings towards the other in psychotherapeutic interactions (for example Scheflen 1964, Winters 2008), the precise role of mirror neurons in empathic engagement is not identified. It is likely that, while mirror neurons aid kinaesthetic empathy, their activation is not sufficient in itself to explain the psychotherapeutic use of empathy, which includes a more sophisticated and holistic engagement than mere sensory-motor activity.

Vitality was one of the healing processes identified by Schmais 1985 in her foundational theoretical article concerning group DMT. She defines 'vitalization' (p. 25) as “investing people with the power to live" and goes on to suggest that the 'animation' observed in infants is sometimes blocked or diverted during the process of maturation; thus, many patients seen by dance movement therapists lack this 'vitality'. The blocking of energy (linked to Wilhelm Reich's concept of chronic tension as body armour) results in a waste of energy: "distorted bodies and ... awkward, inefficient movements" (Schmais 1985 p. 25). Schmais argues that DMT can help release this armour and thus renew vitality. This proposition was given some support by Ehrhardt 1989, who interviewed outpatients and asked them to watch video representations of each of Schmais' healing processes within a DMT group in which they had participated, ranking them in terms of which they liked most and least. Vitalization was the most valued process. However, this does not necessarily mean that it was effective in reducing depression. More recently, Koch 2007 claims to have demonstrated a statistically significant decrease in depression and increase in vitality within a group of people who had been clinically diagnosed as having depression and who participated in circle dances with jumping rhythms, as compared to exercise and music controls. Both circle dance forms and jumping rhythms are common ingredients of DMT sessions. Koch used a scale, the Heidelberger Befindlichkeitsskala, previously tested and shown to have internal consistency with a Cronbach's alpha of 0.89 (mean of pre-test to post-test). The scale has a subscale for vitality (alpha $=0.89$ ) in which the individual self rates on a scale of 1 to 9 from 'lifeless, empty' to 'full of life'. Depression was similarly scored, from 'depressive' to 'not depressive', using the depression subscale (alpha $=0.72)$ of the same instrument. However, the statistical analysis was based on the differences from pre- to post-testing. Taking their end results as the comparison, the depression and vitality scores are not significantly different at the end of study between the DMT and control groups, at 95\% confidence interval (CI) [Dance, $\mathrm{n}=11$ : depression 3.59, SD 0.81; vitality 5.82, SD 1.41. Music, $\mathrm{n}=10$ : depression 4.00, SD 0.97; vitality 5.95, SD 1.33. Exercise, $n=10$ : depression 4.60, SD 1.65; vitality 5.35, SD 1.68]. The proposed link between DMT, increased vitality and a reduction in depression thus remains unproven.

Schmais 1985 also argued that symbolism is responsible for therapeutic change. Symbolism is often associated with movementbased imagination and movement as metaphor, all integral components of the creative process (Karkou 2006; Meekums 2012). For example, as early as 1981 Dosamantes-Alperson 1981 argued for the value of activating imagination through movement in DMT. Karkou 2006 argues that imagination can be manifested as

Dance movement therapy for depression (Review) 
a communicative expression in symbolic movement. Furthermore, working creatively with symbolic movement may enable participants to communicate difficult and distressing material which is difficult to communicate verbally (Karkou 2006), which can lead to a shift in cognitions and feelings (Meekums 2002). Meekums 2002 argues that 'movement metaphor' is a useful device since it serves both to decrease emotional distance between the therapist and client and to increase emotional distance from distressing memories and feelings; metaphors also inherently contain the potential for change and development.

Other healing processes referred to by Schmais 1985 include synchrony, expression, rhythm, integration, cohesion and education, all echoing the therapeutic factors in group psychotherapy proposed by Yalom 2005. It is possible that both Schmais' healing processes in DMT and Yalom's therapeutic factors are in complex and simultaneous operation during DMT. Embodiment literature (for example Gibbs 2005; Niedenthal 2006) suggests that therapeutic factors are enhanced by sensory-motor experiences.

For clients faced with depression or depressive symptoms, DMT may have positive effects for a number of other reasons. For example, mood may be elevated because the use of dance movement has an element of exercise (albeit often rather gentle) for which there is already evidence of an impact upon depressive symptoms, as reported in the exercise research literature (NICE 2010; Rimer 2012). Many forms of DMT also involve the use of music. An existing Cochrane review of music therapy (Maratos 2008) suggests possible benefit, although it cannot be assumed that when music is used as part of another kind of therapy this finding will still be valid since music therapy uses music in a very specific way. Reviews of verbal psychological therapies indicate that there are benefits from the use of short-term psychodynamic psychotherapy for common mental health problems (Abbass 2006); psychotherapy for older people with depression (Wilson 2008); and psychosocial and psychological therapies for antenatal and postpartum depression (Dennis 2007a; Dennis 2007b). Since dance movement therapists often draw upon psychotherapeutic theoretical frameworks for their practice, these reviews might be relevant.

However, none of the above addresses the unique features of DMT that may be responsible for any psychotherapeutic effects on people with depression. The embodied nature of DMT makes it potentially relevant to those clients for whom body image or body memory may be a particular issue requiring exploration and working through (Meekums 2002). However, non-randomised evaluation research by Heimbeck 2011 studied two different forms of DMT with patients who had depression ( $\mathrm{n}=103$, Beck Depression Inventory $(\mathrm{BDI})>18$ ) where one DMT approach was specific to the disorder and the other was non-specific. Both forms were deemed effective and the authors concluded that general disorder non-specific (though potentially specific to DMT) determinants play a more important role in therapeutic success than assumed so far. This would appear to conflict with the Koch 2007 findings. No studies comparing dance or DMT with evidence-based verbal psychotherapies have so far been located.

\section{Why it is important to do this review}

Current evidence-based treatments recommended in the UK by the National Institute for Health and Care Excellence (NICE 2010) include a stepped care model, in which the least intrusive and most effective treatment is offered first, with others only being offered if this proves ineffective. Medication is not normally advised for those with only mild or subthreshold depression due to a poor risk-benefit ratio. If low-intensity psychological therapies do not work, the other evidence-based treatments available include selective serotonin reuptake inhibitors (SSRIs), cognitive behavioural therapy (CBT) (and with a lower evidence base, certain other behavioural treatments), interpersonal therapy (IPT), or a combination of these (NICE 2010). In practice, most people will be offered a combination of low intensity (CBT-based) psychosocial interventions; and for those with a history of moderate or severe depression or persistent symptoms, anti-depressant medication (normally an SSRI, and in some cases tricyclic antidepressants (TCAs), monoamine oxidase inhibitors (MAOIs) or mood stabilisers including lithium). Physical activity is also recommended as a low-intensity intervention.

The evidence, however, for these recommended treatments is not unequivocal. For example, a Cochrane systematic review (Arroll 2009) found that, while anti-depressant medication was found to be more effective than a placebo, there was evidence of publishing bias. Disadvantages to pharmacological treatments are that they may have adverse side effects, TCAs being associated with more adverse effects than SSRIs (Arroll 2009); adherence can be poor (Pampallona 2002); and there is a lag time between starting treatment and any clinical improvement (Pampallona 2002; Arroll 2009). They are also expensive compared to non-pharmacological treatments (Antonuccio 1997; Vos 2005).

A Cochrane systematic review of psychosocial and psychological therapies for postpartum depression (Dennis 2007a) found that any psychosocial or psychological therapy, when compared with usual postpartum care, was associated with a reduction in depression within the first year postpartum. While there is some evidence that IPT may be superior to a parenting education programme in treating antenatal depression, the evidence remains inconclusive (Dennis 2007b). A Cochrane systematic review of psychological therapies for older people who are depressed (Wilson 2008) concluded that CBT may be of benefit, although there was no significant difference in treatment effect between psychodynamic therapy and CBT in the three trials reviewed. A Cochrane review by Rimer 2012 indicated that there is evidence of a small positive effect of exercise. However, while Rimer 2012 conducted a subgroup analysis for type of exercise this only looked at aerobic, resistance, and mixed. There was no examination of different types of aerobic exercise. In addition, most of the trials reviewed had 
methodological weaknesses and the effect size was clinically small when only studies of higher methodological quality were included. The most readily available treatments may not be suitable for everyone, either for reasons of side effects, cost or personal preference. For example, some patients may worry about medication side effects. What in the UK is often referred to as counselling (which developed initially from humanistic therapies including the teachings of Carl Rogers but today includes several different schools of thought including psychodynamic psychotherapy, cognitive behavioural therapy and an integration of all three major schools) was at one time included as a recommended treatment for depression, although the most recent NICE 2010 guidelines for England and Wales now only recommend this in cases where the patient has declined other treatments with a more robust evidence base, including CBT, certain behavioural treatments, IPT and anti-depressant medication. Not everyone can engage with CBT or IPT, both of which may require considerable cognitive and linguistic skills together with a particular way of thinking about problems. For some, verbal articulation of thoughts and feelings may be challenging for one or more of the following reasons: inadequate language skills; cultural differences; intellectual inadequacy; fear of addressing painful experiences; because the problems originate in pre-verbal experience; because the problems are so complex as to be (initially at least) beyond words.

There is therefore a need for a broader range of evidence-based treatments, including those that can be applied across cultures and with people who may find it difficult to verbally articulate their thoughts and feelings.

Arts therapies (that is art therapy, dance movement therapy, drama therapy and music therapy) are less common treatment options for people faced with depression, and scientific evidence for their effectiveness remains limited. The only available Cochrane systematic review of arts therapies for this population has been in music therapy (Maratos 2008). The review concluded that music therapy is an acceptable treatment, as demonstrated by few dropouts. Studies suggested improvements in mood; however methodological weaknesses in the studies reviewed led to the conclusion that there was insufficient evidence to be able to establish effectiveness.

There have been few systematic reviews of evidence concerning DMT. A Cochrane review of DMT for schizophrenia (Ren 2013) found only one study that was of a sufficiently high methodological quality to include (Röhricht 2006). This study, which compared DMT plus standard care to standard care alone, demonstrated a $20 \%$ reduction in negative symptoms such as social withdrawal, apathy, inability to experience pleasure and defects in attention control; symptoms that are closely linked with those of depression. The Cochrane review protocol of DMT for cancer care (Bradt 2010) also suggests possible effects in reduction of isolation and depression (Dibbell-Hope 2000; Mannheim 2006). A recent meta-analysis of DMT (Koch 2014) found a moderate effect of DMT for a range of clinical conditions, including depres- sion. However, none of these reviews exclusively focused on DMT for depression. An initial scoping review of the literature, which searched for studies using the key words 'dance movement therapy' and 'depression' (Mala 2012), suggests that there is some empirical research concerning the effectiveness of DMT for depression. It was expected that more studies would be revealed through a more extensive search.

This review was designed to further understanding of the research evidence in DMT beyond that available for schizophrenia (Ren 2013) and cancer care (Bradt 2010). The Cochrane Collaboration Depression, Anxiety and Neurosis Review Group is currently working on other systematic reviews that address psychological therapies for depression (Hunot 2010; Churchill 2010a; Churchill $2010 \mathrm{~b}$ ), and this review will therefore add to a growing body of evidence in the treatment of depression. It will also add to completed reviews relating to this client group, in music therapy (Maratos 2008), exercise (Rimer 2012), and psychotherapy (Abbass 2006; Dennis 2007a; Dennis 2007b; Henken 2007; Wilson 2008).

\section{O B JE C T IVES}

1. To assess the effects of dance movement therapy (DMT) plus either no treatment or standard care for depression compared with no treatment or to standard care alone, in both child and adult populations

2. To compare DMT with other psychological therapies (e.g. psychodynamic, humanistic, cognitive behavioural (CBT) and integrative therapies)

3. To compare DMT with pharmacological interventions (e.g. antidepressants, minor tranquillisers or mood stabilisers)

4. To compare DMT with other physical interventions (e.g. dance or exercise)

5. To compare different forms of DMT (e.g. Laban-based DMT, Chace methods of DMT or Authentic Movement) (see below for explanations of these)

\section{METHODS}

\section{Criteria for considering studies for this review}

\section{Types of studies}

All randomised-controlled trials (RCTs) of dance movement therapy (DMT) for depression, whether published or unpublished and in any language, were eligible for entry. Since we were working in an area where there was relatively very little evidence (as indicated 
by the scoping review performed by Mala 2012), cross-over designs were considered, up to the point of cross-over. Cluster RCTs were considered using best practice guidance from the Cochrane Handbook for Systematic Reviews of Interventions (Higgins 2011). We were also prepared to consider trials for which there was an evident clustering effect, for example individual randomisation but to the same therapist. In this case we intended to reduce to an 'effective sample size' as suggested in section 16.3.4 and 16.3.5 of Higgins 2011. Trials with quasi-randomisation or systematic methods of allocation (for example alternate allocation of treatments) were also eligible for inclusion. The rationale for this decision was that historically DMT has been an under-evaluated area (in terms of using what is recognised as best practice in evaluation of interventions) so we were prepared to consider less robust designs and place them in the context of the emerging body of evidence.

\section{Types of participants}

Participants were those with symptoms of depression as defined by the trialist. This could be defined clinically following either a recognised diagnostic manual such as the International Statistical Classification of Diseases and Related Health Problems (ICD-10) (WHO 2010b), the Diagnostic and Statistical Manual of Mental Disorders (DSM-IV-TR) (APA 2000), or using a standardised measure and scoring above the cut-off point on self-rated or clinician-rated valid and reliable scales, for example: the Beck Depression Inventory (Beck 1961); the Symptom Check List-90-Revision (SCL-90-R) (Derogatis 1977); or the Hamilton Rating Scale for Depression (HAM-D) (Hamilton 1960). Cut-off scores were those the authors of these scales had defined as such. It was expected that this criterion would be present at the start of the trial. We excluded trials involving participants with chronic or treatment-resistant depression, or participants at risk of relapse. We also excluded studies in which the primary diagnosis was either a physical condition or other psychiatric diagnosis with depression secondary, though we considered studies for inclusion where there was a comorbid physical or common mental disorder so long as these were secondary to the diagnosis of depression. There were no restrictions in terms of age, gender or ethnicity nor in severity of depression. Both inpatients and outpatients were considered and in all settings including both statutory and non-statutory organisations.

\section{Types of interventions}

\section{Experimental intervention}

For a study to be included, the reported intervention had to include active involvement of participants in dance movement in the presence of a therapist; or dance movement interaction with a therapist or other group members; or both. Dance movement could be either improvisatory or structured, with or without music. In all cases, however, sessions had to have a clearly articulated psychotherapeutic intent. For example, in the case of depression this could include the intention of changed perceptions about, and responses to, life events that may have contributed either to the aetiology or maintenance of the condition. In practice, this may be operationalised as a change in depression as assessed either by a psychiatrist or through a valid and reliable self-report tool like the Beck Depression Inventory (Beck 1961). The intervention needed to be facilitated by a practitioner who might have received formal training, be a dance movement therapist in training, or be otherwise accredited in the country in which the study was conducted; for example, some dance movement therapists who have received no formal training are nevertheless deemed to have met registration criteria through a process of 'grandparenting' within the country in which they practise. It is acknowledged that some countries do not yet have processes for registration, and so in these circumstances a lower qualification may be acceptable. However, if sufficient studies were available a sensitivity analysis would be performed to establish the extent to which level of therapist training (where reported) impacted on results.

We considered both group and individual DMT within any number and duration of sessions.

There were a number of different approaches to DMT. Karkou 2006 identifies three models, as follows, though these are not necessarily exhaustive:

(i) Some practitioners rely primarily upon dance movement engagement, e.g. creative movement work primarily informed by an early proponent of therapeutic applications of dance movement, Rudolf Laban (Laban 1975), in order to explore specific movement themes and qualities. Most often this approach involves the therapist directly facilitating a change in the client's movement behaviour based on an assumption that an expansion of a person's functional and expressive movement repertoire enables a broader coping repertoire. The therapist serves as a movement catalyst in this process (Bartenieff 1980)

(ii) There are those that value the non-verbal interaction between client(s) and therapist (interactive work based on principles developed originally by the American DMT pioneer Marian Chace, as described by Chaiklin 1986). In this approach, the therapist (and at times other group members) actively 'mirrors' the expressive movement qualities of clients, aiming to create empathy. This is the basis of the therapeutic movement relationship in which the therapist joins the client in movement and re-enacts and amplifies essential constellations of the client's movement to bring them to fuller expression. Body action, symbolism, and rhythmic group activity are additional core aspects of this work.

(iii) Others encourage internal work in the presence of a therapist, such as Authentic Movement which originated with the American choreographer Mary Whitehouse and is influenced by Jungian psychology (Whitehouse 1979). In Authentic Movement, initially termed 'movement in depth', the therapist stays still and observes, 
using his/her self as an empathic witness. Authentic Movement cultivates a client's inner listening to bodily sensations and impulses. Inner experience is expressed and explored through improvisational movement in the presence of a therapist. The process is focused on discerning personal movement patterns and their meanings in the service of self integration (Whitehouse 2000).

In all cases, dance movement is used within a well-defined psychotherapeutic relationship, that is a relationship between the client and therapist with or without others, and with psychotherapeutic intent. The therapist may be active (moving with participants, as in the use of Chace methods) or adopt a more observational stance (as in Authentic Movement). In all cases this involves an embodied empathic relationship. In addition to this empathic engagement, the therapist's body may act as a container for intersubjective phenomena (e.g. painful emotions) that can be worked through on the non-verbal or verbal level, or both. Verbal reflection on the individual meanings associated with movement may form an integral part of DMT sessions. As a result, studies of dance classes in which no psychotherapeutic relationship or psychotherapeutic intent was identified were excluded.

\section{Comparators}

1. No treatment or standard care

The review intended to include all studies in which any form of DMT plus either no treatment or standard care was compared with no treatment or standard care alone. In the case of no treatment, studies included could compare DMT with people either recruited from the community or placed on waiting lists without receiving standard care. Studies where standard care as defined by the trialists was available were also considered .

2. Psychological therapies

Psychological therapies such as psychodynamic, humanistic, cognitive behavioural (CBT) and integrative therapies were considered as appropriate controls for either DMT alone or in combination with standard care.

3. Pharmacological interventions

Studies that compared DMT with anti-depressant medication such as selective serotonin reuptake inhibitors (SSRIs), tricyclic antidepressants (TCAs) or monoamine oxidase inhibitors (MAOIs) could be included. Other minor tranquillisers such as benzodiazepines and mood stabilisers such as lithium were also considered, if relevant.

4. Physical interventions

Studies that compared DMT with physical interventions such as exercise or dance could be considered.

5. Different types of DMT

Different types of DMT, as defined above, could be considered as potential comparators.

\section{Types of outcome measures}

\section{Primary outcomes}

1. Level of depression, as measured through a valid and reliable scale or self-rated measurement such as, but not limited to: the Beck Depression Inventory (Beck 1961); the Symptom Check List-90-Revision (SCL-90-R) (Derogatis 1977); or a clinician-rated scale such as the Hamilton Rating Scale for Depression (HAM-D) (Hamilton 1960). Continuous outcomes of depression improvement were used; we also planned to analyse outcomes which the trialist had dichotomised. We referred to the literature on the standardised measure used in order to determine what was a Minimal Clinically Important Difference (MCID) between baseline and post-treatment score.

2. We also planned to report drop-out rates, where available, as a measure of treatment acceptability (high drop-out rates being seen as a measure of potential harm because they suggest unacceptability).

\section{Secondary outcomes}

1. Social and occupational functioning (e.g. engagement in social activities (Tyrer 2005)).

2. Quality of life (e.g. WHOQOL-BREF (WHO 2004)).

3. Self esteem (e.g. Rosenberg 1965).

4. Body image (e.g. the Body Image Quality of Life Inventory (Cash 2002)).

5. Cost effectiveness of treatment, as measured by the trialist. In all cases, validated measurements were preferred over non-validated measurements, especially when different measurements were used for the same outcome. Were there sufficient data, we planned to report on outcomes measured at various time points, as follows: 1. End of intervention.

2. Short-term follow up (up to and including three months after intervention end)

3. Medium-term follow up (more than three months, and up to and including six months after intervention end)

4. Long-term follow up (more than six months after intervention end)

\section{Adverse events}

We planned to summarise adverse events quantitatively or qualitatively depending on the information available in trial reports. This might include, for example, a worsening of symptoms as identified using the measures identified above, or injury.

\section{Search methods for identification of studies}

\section{The Cochrane Depression, Anxiety and Neurosis Review Group's Specialised Register (CCDANCTR)}

The Cochrane Depression, Anxiety and Neurosis Group (CCDAN) maintain two clinical trials registers at their editorial base in

Dance movement therapy for depression (Review) 
Bristol, UK: a references register and a studies-based register. The CCDANCTR-References Register contains over 37,000 reports of RCTs in depression, anxiety and neurosis. Approximately $60 \%$ of these references have been tagged to individual, coded trials. The coded trials are held in the CCDANCTR-Studies Register and records are linked between the two registers through the use of unique Study ID tags. Coding of trials is based on the EU-Psi coding manual, using a controlled vocabulary; please contact the CCDAN Trials Search Coordinator for further details. Reports of trials for inclusion in the Group's registers are collated from routine (weekly), generic searches of MEDLINE (1950 to date), EMBASE (1974 to date) and PsycINFO (1967 to date); quarterly searches of the Cochrane Central Register of Controlled Trials (CENTRAL); and review-specific searches of additional databases. Reports of trials are also sourced from international trials registers via the World Health Organization's trials portal (the International Clinical Trials Registry Platform (ICTRP)); pharmaceutical companies; the handsearching of key journals; conference proceedings; and other (non-Cochrane Collaboration) systematic reviews and meta-analyses.

Details of CCDAN's generic search strategies (used to identify RCTs) can be found on the Group's web site.

\section{Electronic searches}

The CCDANCTR Registers were searched by the Group's Trials Search Co-ordinator (TSC) to 2 October 2014.

The CCDANCTR-Studies Register was searched using the following controlled vocabulary terms: Condition $=\left(\right.$ depress ${ }^{*}$ or dysthymi*) AND Intervention = "dance therapy"

The CCDANCTR-References Register was searched using a more sensitive set of free-text terms to identify additional untagged/ uncoded references:

(depress* or dysthymi* or "adjustment disorder*" or "mood disorder" or "affective disorder*" or "affective symptom*") AND (danc* or "authentic movement" or "movement therap*" or "movement psychotherap*” or "body psychot*”)

The first two review authors conducted complementary searches, using AMED, CINAHL, ERIC and Dissertation Abstracts, that were initially completed 7 December 2012. Further searches were carried out in August 2013 and the CINAHL search was again updated to 2 October 2014, Details of the search strategies used are given in Appendix 1.

International trial registers (ClinicalTrials.gov and the WHO trials portal (ICTRP)) were also searched to 2 October 2014.

\section{Searching other resources}

In an effort to identify further published, unpublished and ongoing trials the first two review authors searched the ICTRP and ClinicalTrials.gov (12 July 2013), using the same terms as the CCDAN search. They also:

1. searched reference lists of relevant studies and reviews;
2. contacted professional associations and educational programmes in DMT from around the world including those in the USA, Australia, Europe (the UK, Ireland, the Netherlands, Germany, Austria, Czech Republic, Poland, Latvia, Sweden, Finland, Russia, Greece, Cyprus, Slovenia, Italy, France, Israel, Spain and Portugal), Israel, Korea, and Japan, asking members to inform us about published and unpublished research studies including Masters and $\mathrm{PhD}$ work that met the inclusion criteria, using a standard letter (Appendix 2);

3. contacted experts in the field, using a standard letter (Appendix 2)

\section{Data collection and analysis}

\section{Selection of studies}

Two members of the review team (BM, VK) screened titles and, where available, abstracts of all studies for inclusion according to the inclusion criteria identified above (Criteria for considering studies for this review). The same two review authors obtained full reports for trials appearing to meet the inclusion criteria and for which there was insufficient information in the title and abstract to make a clear decision.

Two review authors (BM, VK) each independently assessed 14 full reports to establish whether the trial met the inclusion criteria or not. Disagreements were resolved by discussion; where this did not result in agreement and in the case of a study in which one of the two review authors was involved as a researcher, the third member of the review team (AN) was involved. Records were kept of full papers and of the reasons for inclusion and exclusion, stating the stage at which this decision was made.

\section{Data extraction and management}

Two review authors (BM, VK) each independently extracted data using a specially designed data extraction form (See Appendix 3). Disagreements were resolved by discussion; where issues remained unclear, the third member of the review team (AN) arbitrated. In the first instance, we extracted data relating to the following categories:

1. General information.

2. Eligibility criteria. An interim decision was recorded as follows: inclusion, exclusion or requiring more information from the authors. The final decision was then recorded, after inclusion of additional information obtained. In this second stage, more detailed information as below was extracted as indicated in the data extraction form presented in Appendix 3.
3. Study characteristics.
4. Interventions.
5. Outcome measures used in the study.
6. Study results. 
7. Additional notes.

8. Main comparisons

\section{Main planned comparisons}

1. DMT versus no treatment and DMT with or without standard care versus standard care;

2. DMT versus other psychological therapies (e.g. psychodynamic, humanistic, cognitive behavioural (CBT) and integrative therapies);

3. DMT versus pharmacological interventions (e.g. antidepressants, minor tranquillisers and mood stabilisers);

4. DMT versus other physical interventions (e.g. dance or exercise); and

5. One form of DMT versus another (e.g. Laban-based DMT versus Chace methods of DMT or Chace methods of DMT versus Authentic Movement).

\section{Assessment of risk of bias in included studies}

Two review authors (BM, VK) each independently conducted a 'risk of bias' assessment. We solved any disagreements through discussion. The review authors recorded a judgement of 'low risk', 'high risk' or 'unclear risk' of bias for each of seven domains, using a proforma designed for this purpose (see Appendix 3) (Higgins 2011). The main areas covered were:

1. Random sequence generation;

2. Allocation concealment;

3. Blinding of participants and personnel;

4. Blinding of outcome assessment;

5. Incomplete outcome data;

6. Selective reporting; and

7. Other sources of bias.

We did not exclude studies based on a high risk of bias.

\section{Measures of treatment effect}

The levels of depression were measured using rating scales presented as dichotomous or continuous outcomes. For continuous outcomes, such as scores from a scale and those that come from the same scale, we used mean differences (MD) between the posttreatment scores of the DMT and comparison groups. Had there been sufficient homogeneity for outcomes from different scales to be combined, we planned to use standardised mean differences (SMD). If study results had been presented as dichotomous outcomes, we intended to summarise these as the number of people achieving a minimum clinically-significant reduction in level of depression, using odds ratios (OR). If sufficient data had been available to pool both dichotomous and continuous outcomes, we intended to do so using the formula recommended in section 9.4.6 of Higgins 2011.

Two review authors (AN, BM) intended to perform a meta-analysis on the extracted data if:
- more than one study was included with an estimated treatment effect;

- there were minimal differences in characteristics across studies, or these characteristics had been identified a priori and investigated as a potential source of heterogeneity in subgroup analyses;

- the same outcomes had been measured using validated scales; and

- data in each study were available.

If different scales had been used to measure the same outcome, we intended to enter data into Review Manager 5 (RevMan 5; RevMan 2012) to summarise outcomes across scales using the standardised mean difference. It was expected that studies would have used different time points for measurement. If sufficient data were available, we planned to conduct a meta-analysis with planned subgroup analysis to look at different time points: short followup (up to 14 weeks); moderate follow-up (15 to 27 weeks); and long follow-up (28 weeks and over). If there were marked variations in the interventions offered, the populations studied and the outcome measures used, we intended to develop a narrative description of the findings of individual trials.

\section{Unit of analysis issues}

We intended to include cross-over trials, only using the first active treatment period. For studies with multiple arms, only those with DMT and the control would be included in the analysis. If there were two DMT arms with a single control group (for example a dose study), then prior to the meta-analysis we would halve the effective sample size of the control in order to avoid counting the same participants twice.

In the case of cluster randomisation, we intended to conduct the analysis at the same level as the allocation, using a summary measurement from each cluster. The sample size would then be treated as the number of clusters in order to avoid unit-of-analysis errors.

\section{Dealing with missing data}

Where individuals were missing from end of treatment scores, we contacted the trialist in the first instance in an attempt to obtain the missing data and the reason for this. If data were unavailable and unlikely to be 'missing at random' (Higgins 2011, 16.1.2), and provided that the individuals concerned did receive the intervention to which they were allocated, we assumed that the individuals had dropped out from the treatment, which offered some indication of its acceptability (calculated as a percentage drop-out).

Where standard deviations (SD) were unavailable, we aimed in the first instance to calculate this from reported $P$ values, $t$ values, standard errors, $\mathrm{F}$ values and confidence intervals. Where this was not possible, we intended to look for other studies reporting a SD that would allow us to impute this figure, assuming the highest value. It was noted, however, that this strategy could bias towards 
lack of effect. In this case, we intended to perform sensitivity analyses for all imputed measures.

Where authors described an intention to treat (ITT) analysis, we scrutinised the data and where necessary contacted the authors to determine whether this was in fact so, with means and standard deviations of the outcome for all randomised participants available, or whether some other system had been used, for example an available case analysis or ITT using imputed data (Higgins $2011,16.2 .3)$. If raw data had been available for the ITT analysis, we intended to treat missing data cautiously, assuming no change since the last available measurement (continuous outcomes) or no change overall for dichotomous outcomes. This was because in a depression trial, those individuals who did not attend for their endof-treatment measurements may have had a relapse of their depression. Any analysis of the available data without adjustment for this could be biased. We therefore planned to impute missing data with replacement values, treating these as if they were observed by carrying the last measurement forward. All missing data were reported in 'Risk of bias' tables. Given that genuine ITT analyses tend to bias towards no difference, because they include participants who were randomised to the treatment group but received something else, we intended to perform both an available case and imputed data analysis and to carry out a sensitivity analysis, using a fixed difference between the actual mean for the missing data and the mean assumed by imputation. (Higgins 2011, 16.2.3).

\section{Assessment of heterogeneity}

Initially, the review authors intended to inspect studies to identify sources of clinical heterogeneity. Tables were constructed to summarise studies in terms of participants, settings, method of delivery (that is group or individual, number of sessions), type of DMT used, and outcomes presented. In the case of studies that appeared to be clinically similar, a further analysis of statistical heterogeneity was performed. Heterogeneity was initially identified visually (if confidence intervals were not overlapping, this indicated heterogeneity). When appropriate, we intended to apply the $\mathrm{Chi}^{2}$ test. If $\mathrm{Chi}^{2}$ is greater than the degrees of freedom (which is one less than the number of studies in the forest plot) then heterogeneity is present. We assumed that some statistical heterogeneity was inevitable, and thus the $\mathrm{I}^{2}$ statistic (Higgins 2002) was also calculated in order to assess its impact on any meta-analysis (Higgins $2011,9.5 .2)$, using overlapping bands as follows.

- $\mathrm{I}^{2}=0 \%$ to $40 \%$ : might not be important.

- $\mathrm{I}^{2}=30 \%$ to $60 \%$ : may represent moderate heterogeneity.

- $\mathrm{I}^{2}=50 \%$ to $90 \%$ : may represent substantial heterogeneity.

- $\mathrm{I}^{2}=75 \%$ to $100 \%$ : considerable heterogeneity.

Despite these figures, for psychological assessments it could be acceptable to pool studies with up to $80 \%$ heterogeneity. However, we intended to remove studies of low methodological quality and to perform a sensitivity analysis.

\section{Assessment of reporting biases}

Where evidence of missing outcomes was found, attempts were made to obtain available data direct from the trial authors. We considered the studies for reporting biases, including whether only positive results were published and whether they were published more rapidly. We also considered whether English publications included more positive results than those in other languages, and we considered citation bias and outcome reporting bias. We intended to use a funnel plot analysis to examine publication bias if there were more than 10 studies addressing a particular question.

\section{Data synthesis}

We entered all trials included in the systematic review into RevMan 5.2.

Based on the potential heterogeneity of populations and interventions, the true effect was expected to be related but not all the same for studies to be included in the review. We therefore intended to use a random-effects model for all analyses, but to undertake a sensitivity analysis using a fixed-effect model.

\section{Subgroup analysis and investigation of heterogeneity}

If possible, we intended to perform subgroup analyses by mode of delivery including:

- group or individual;

- moving or non-moving therapist;

- length of treatment including number of sessions (session number of fewer than 12, 12 and more);

- intensity of intervention, to include frequency (weekly or less frequent, bi-weekly or more frequent) and duration of sessions (one hour or less, more than one hour);

- severity of depression at start of treatment (mild, moderate or severe, as identified by the trialist using standardised measures);

- participant characteristics including gender (men, women or other); and age (under 18 years or child or adolescent however determined by the trialist; 18 to 64 years or adult however determined by the trialist; 65 years and over or older adult however determined by the trialist);

- setting (statutory, as in NHS or other main health provider; and non-statutory, as in voluntary agency or charity).

\section{Sensitivity analysis}

We intended to include all studies meeting the criteria, irrespective of methodological quality. However, in order to examine any effects of methodological decision on the overall outcome, we intended to perform a sensitivity analysis, as follows, provided that sufficient numbers of studies were identified:

1. Different designs.

- a) Excludiing quasi-RCTs (with systematic methods of allocation) 
- b) Excluding cross-over designs

- c) Excluding cluster RCTs and other cluster effects including randomisation but to the same therapist.

2. Excluding those studies with high risk of bias, for example due to poor allocation concealment.

3. For ITT: comparing those studies with imputed measures to those using an available case analysis and 'as treated'.

4. Excluding other identified low methodological quality studies (for example, the treatment therapist having a low level of training in country where registration criteria do not so far exist).

\section{RE S U L T S}

\section{Description of studies}

\section{Results of the search}

The total number of studies identified through searches was 602 (608 references).

Of these, the search of the Cochrane Collaboration Depression, Anxiety and Neurosis Controlled Trials Register (CCDANCTR) identified 50 studies represented by 55 references $(30$ references and 28 studies in February 2012; 14 references and 12 studies in July 2013; and 11 references and 10 studies in October 2014). Of the studies identified in the second CCDANCTR search, two (both references) had previously been identified through personal communications. One of the references identified at the third CCDANCTR search had previously been identified through the first CINAHL search.

540 records were identified through searches of other databases, which included a repeated search of CINAHL in 2014.
One reference was identified through a search of reference lists and 11 studies (all references) were identified through personal communications. One additional reference was located through a general library search in 2014 , as a result of consulting the detail of one of the excluded studies from the first CCDANCTR search, which had mentioned that results would be published at a later date.

Fifty-seven records were screened at the title and abstract stage, the remainder (551) either being duplicates or being considered to be 'noise'. Noise was defined either as: the intervention clearly not being DMT (nothing; bodywork that is clearly not DMT such as Feldenkrais or other non-dance based bodywork; specified nondance exercise such as running; massage; an easily identified alternative intervention such as cognitive-behavioural or behavioural interventions; mentoring; education; occupational therapy; physiotherapy/physical therapy; or drug treatments); or the population clearly did not have a primary diagnosis of depression (e.g. meniscus injury); or the type of study was clearly not RCT (e.g. systematic review, or case study).

Of the 57 records that were screened using our data extraction proforma as a guide (Appendix 3), 22 were identified through the CCDAN searches, 23 were identified through searches of other databases (CINAHL), one was identified through a reference list and 11 were identified through personal communications.

As a result of this initial screening of title and abstract, 10 studies were excluded on study design, 16 on population, and 6 on intervention. The full text was obtained for 25 records and a further 22 excluded (five on study design; 10 on population; and 7 on intervention). Three studies met the criteria for inclusion in this review, one of which (Xiong 2009) was unique to CINAHL.

Another of the included studies, (Röhricht 2013), was initially identified by personal communication (13 May 2012), but the published report was also included in the CCDANCTR update (July 2013)

The study selection process is summarised in Figure 1. 
Figure I. PRISMA flow diagram

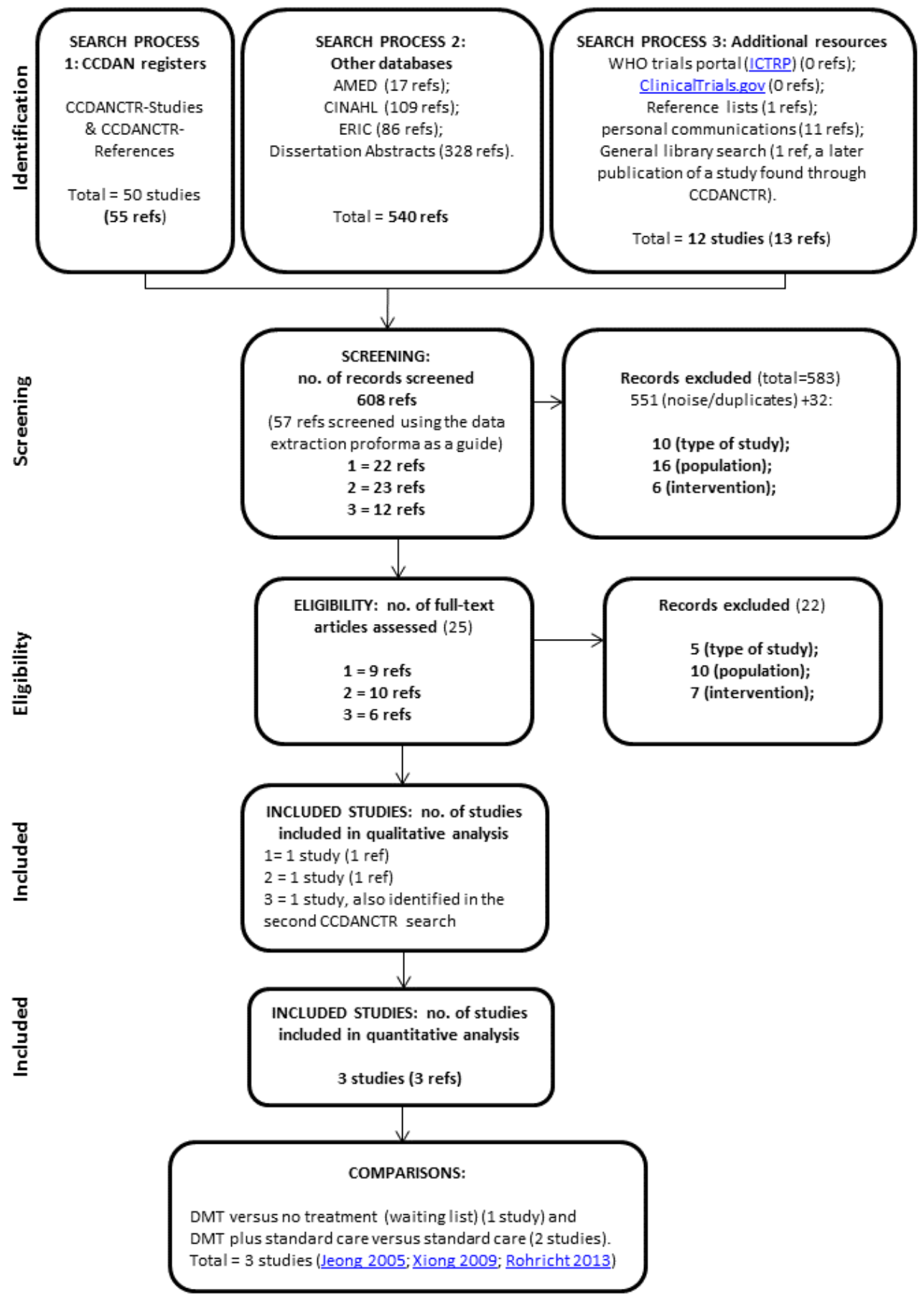

Dance movement therapy for depression (Review) 


\section{Included studies}

The Characteristics of included studies tables summarise the three included studies, which are also described below.

\section{Design}

All three studies used RCT design. Röhricht 2013 modified this to a cross-over design.

\section{Sample sizes}

A total of 147 people participated in the three studies. Seventyfour took part in DMT treatment, while 73 comprised the control groups.

\section{Setting}

The three included studies took place in three different countries (UK, Korea and China) and in three different settings; a middle school (Jeong 2005), adult psychiatric outpatients (Röhricht 2013), and an urban hospital (Xiong 2009).

\section{Participants}

There were 96 women and 51 men participating in total. One study (Jeong 2005) recruited all females. The other two studies (Xiong 2009 and Röhricht 2013) recruited both males and females and in those studies gender was reasonably balanced with 56 women and 51 men participating.

The age of the participants varied. For the adolescent study (Jeong 2005) the average age of participants was 16 (no range was available). For the adult studies the average age of participants was 40 ranging from people aged 23 to 58 years $(32.26 \pm 8.71$ yrs Xiong 2009; $47.7 \pm 10.4$ Röhricht 2013).

In terms of severity of depression, it is possible to compare the two adult studies but not to compare this with the adolescent study, which used a different measure. As one might expect in the difference between a hospital group and an outpatients group, the Xiong 2009 study included people with more severe depression than the Röhricht 2013 study, though for both studies this was in the very severe range at the start of the study.

In the adolescent study (Jeong 2005), the participants were all diagnosed with depression on the basis of: (i) their scores on the Beck Depression Inventory (Beck 1961) (ii) a pre-treatment assessment of symptoms that lasted four weeks. Severity of depression is not reported other than the fact that in the first instance 112 participants with the highest scores of depression were selected out of the initial sample of 300 who completed the initial questionnaire.
High levels of depression were also apparent in the scores reported from the SCL-90-R measure, especially for the DMT group.

\section{Interventions}

In all three studies, the design involved random allocation of participants to DMT as the intervention versus a control group that either received no treatment (Jeong 2005), or received standard care (Xiong 2009; Röhricht 2013). In the two studies for which the control group received standard care, the intervention group also received standard care. In both cases, this included medication; for Xiong 2009 standard care also included psychological nursing support, and for Röhricht 2013 outpatient clinical management. In both the Jeong 2005 and the Röhricht 2013 studies the control groups were treated as waiting list groups that received DMT once the study intervention was completed. In the Xiong 2009 study, the control group did not appear to receive DMT at a later stage. The DMT intervention was in all cases delivered in a group format, lasting from four to twelve weeks (Xiong 2009, four; Röhricht 2013, ten; Jeong 2005, twelve). The number of sessions ranged from 20 (Xiong 2009; Röhricht 2013) to 36 (Jeong 2005). The frequency varied from two to five times per week (Röhricht 2013, two; Jeong 2005, three; Xiong 2009, five) with session length equally diverse from 45 minutes to two hours each (Jeong 2005, 45 minutes; Röhricht 2013, 90 minutes; Xiong 2009, two hours). The total time of DMT ranged from 1620 to 2400 minutes (Jeong 2005, 1620; Röhricht 2013, 1800; Xiong 2009, 2400).

The Röhricht 2013 study refers to the intervention as Body Psychotherapy (BPT). On close inspection, the intervention appears to be a form of manualised DMT specifically designed to address symptoms of depression, with influences from body psychotherapy. This included movement-based work, interactive components and insight work. The intervention was designed, delivered and supervised by qualified and experienced dance movement therapists.

More specifically, the key components of the intervention were:

1. Exercises and activities aiming to increase self awareness and psychomotor activity levels;

2. Techniques that were intended to revitalise, process negative/aggressive impulses, enhance affective modulation, encourage bodily resources and support self regulation;

3. Interventions that focused on strengths and capabilities in order to address negative self evaluation, self demarcation and somatic depersonalisation; and

4. Body-based work that focused specifically on individual stories, unmet needs and traumas in order to reconsider selfdestructive tendencies and enable a more constructive attitude. Since the treatment was manualised, there was a particular structure in each session and clear phases guiding the intervention.

Dance movement therapy for depression (Review) 
Sessions in the study by Jeong 2005 were planned around four themes: (a) awareness of body, environment and others; (b) expressive and symbolic movement; (c) the relationship between movement, feeling, images and words; (d) differentiation and integration of feelings. No information is given regarding the training level of the therapist who facilitated the DMT groups, though Korea (where this study was carried out) does have a well developed professional association for DMT and the description of the intervention would tend to indicate professional level training. The Chinese study (Xiong 2009) stated that the intervention used Chace methods of group DMT. Since the four main areas of Chace methods include (a) body action (b) symbolism (c) therapeutic movement relationship and (d) rhythmic activity (Chaiklin 1986; Karkou 2006), the intervention appears to follow Chace methods. In this case, the therapist was a trained nurse who also had counsellor training. The study was included because although DMT in China is still in its infancy, the description of the intervention is similar to that described by Jeong 2005, and Chace is referenced.

\section{Outcomes}

\section{Primary outcomes}

1. Level of depression

In all cases, depression was measured as a primary outcome before and after the intervention for both DMT and control groups. In the Röhricht 2013 study a cross-over design was followed and thus depression levels were measured at three different times (before and after the initial intervention, and after cross-over). In this review, per protocol, only findings up to the point of cross-over were considered. The primary outcome measures used were:

(i) the 21- and 24-item Hamilton Depression Scales (HAM-D) (Hamilton 1960) in the Röhricht 2013 and the Xiong 2009 studies respectively, an observational tool completed by health professionals. The 24-item HAM-D Scale was developed from the 21item HAM-D Scale for Depression to include extra items of clinical use but the additional items are not scored; hence, for research purposes the two scales are comparable as only the first 17 items are used to calculate a score.

The level of depression is estimated from the scores attributed to the first 17 items as follows:

0 to $7=$ Normal

8 to 13 = Mild Depression

14 to $18=$ Moderate Depression

19 to 22 = Severe Depression

$\geq 23=$ Very Severe Depression

(ii) the Symptom Check List-90-Revision (SCL-90-R) (Derogatis 1977), a self-rating scale, used in the Jeong 2005 study. The SCL90-R scale includes a subscale for depression. The study authors do not explain why this more general scale was used for measurement, instead of the Beck Depression Inventory (Beck 1961) that had been used for screening and is a more specific measure for depression.

Continuous outcomes of depression improvement were used; we also planned to analyse outcomes for which dichotomous data was collected. Xiong 2009 did report a dichotomous outcome of 'cure rate', which was calculated as cure rate $=$ number of recovery + number of significant effect, where these cases were defined by reduction in HAMD score, as follows: $\geq 75 \%$ for recovery, $50 \%$ to $74 \%$ for significant effect, $25 \%$ to $49 \%$ for taking a turn for the better and $<25 \%$ for ineffective. While the dichotomous outcome was noted, the continuous outcome (also reported) was used for our analysis, in order to provide a comparison with the other included studies.

None of the studies reported follow-up measures beyond the end of treatment score.

2. We also reported drop-out rates, where available, as a measure of treatment acceptability (high drop-out rates being seen as a measure of potential unacceptability). One of the included studies did not report on drop-out rates (Jeong 2005).

\section{Secondary outcomes}

1. Social and occupational functioning. The SCL-90-R scale includes a subscale for depression and one for interpersonal sensitivity, and this was reported by Jeong 2005.

2. Quality of life. Only one study reported on this outcome: Röhricht 2013 used The Manchester Short Assessment of Quality of Life (MANSA) as their measure.

3. Self esteem. Röhricht 2013 reported this outcome, using our suggested measure (Rosenberg 1965).

4. Body image. No studies reported this outcome.

5. Cost effectiveness of treatment. No studies reported this outcome.

No adverse events were reported in any of the studies reviewed.

\section{Excluded studies}

As indicated in Characteristics of excluded studies, of the 57 records screened, 52 studies ( 54 references) were excluded because of the type of study design, the intervention used or the population participating in the study.

Fifteen studies were excluded on the type of study. Methodologies used in these excluded studies included (i) comparisons between two groups where randomisation was unclear (e.g. Zemite 2011; Lauž a 2011); and (ii) a single case design (Stewart 1994; Payne 2010).

Twenty-six studies were excluded because of the population. Examples are studies where (i) participants were identified from a healthy population where depression was not an inclusion criterion (e.g. Karkou 2010, adolescents at risk; Akandere 2011, conservatory students; Eyigor 2009 and Konstantinidou 2005, older women; Hartshorn 2002, older people in residential homes); and 
(ii) where depression was either present or associated through the literature but secondary to another diagnosis (e.g. Bräuninger 2012, adults with anxiety; Hilf 2009, somatoform disorders; Krantz 1994, healthy students).

Finally, 13 studies were excluded because, under close scrutiny, it became apparent that DMT as per our stated criteria was not used as the intervention. For example, Haboush 2006 used ballroom dance, while Koch 2007 and King 2010 used traditional dances.

\section{Ongoing studies}

An ongoing study (Joseph 2014) that met the inclusion criteria was found, as shown in the table Characteristics of ongoing studies. This is a PhD study that has a mixed methodology dealing with depression amongst adolescents in secondary schools. The second stage of the study involves a pilot RCT. The study has not yet been registered with a Trials Registry or reported outcomes.

\section{Risk of bias in included studies}

See Characteristics of included studies for full details of risk of bias judgements for each study. Graphical representations of the overall risk of bias for included studies are presented in Figure 2 and Figure 3.

Figure 2. Risk of bias graph: review authors' judgements about each risk of bias item presented as percentages across all included studies.

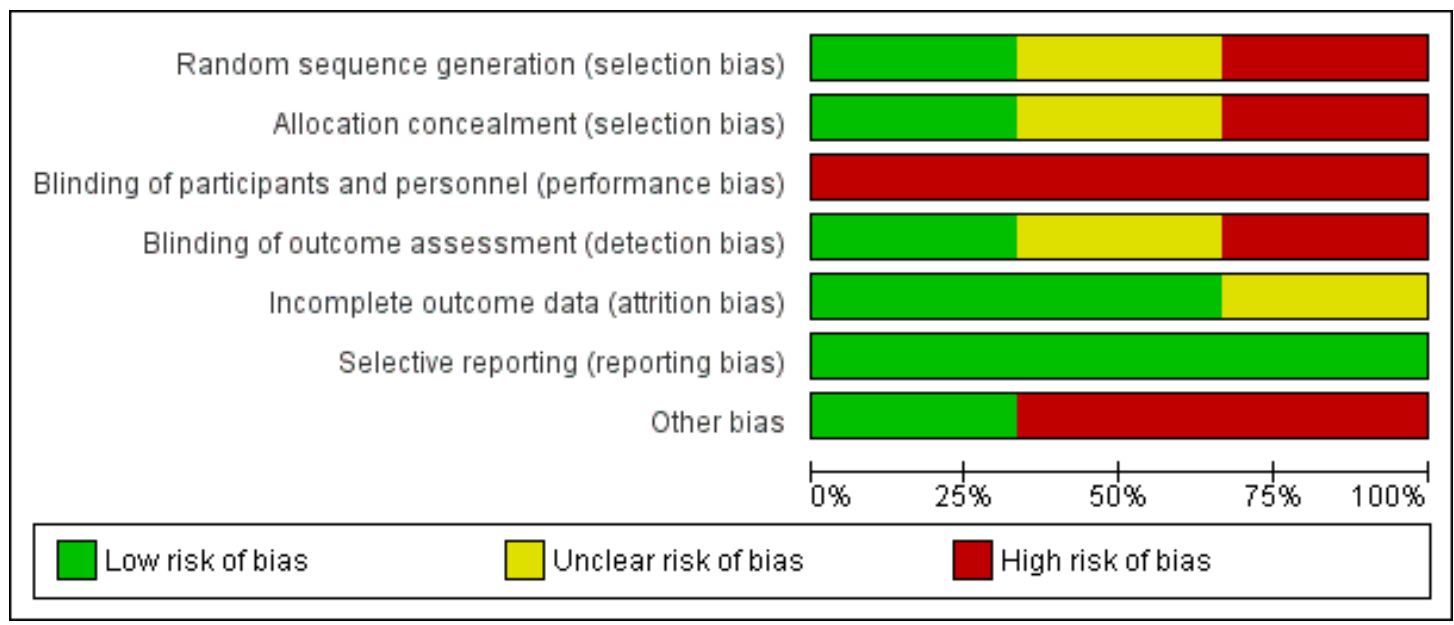

Dance movement therapy for depression (Review) 
Figure 3. Risk of bias summary: review authors' judgements about each risk of bias item for each included study.

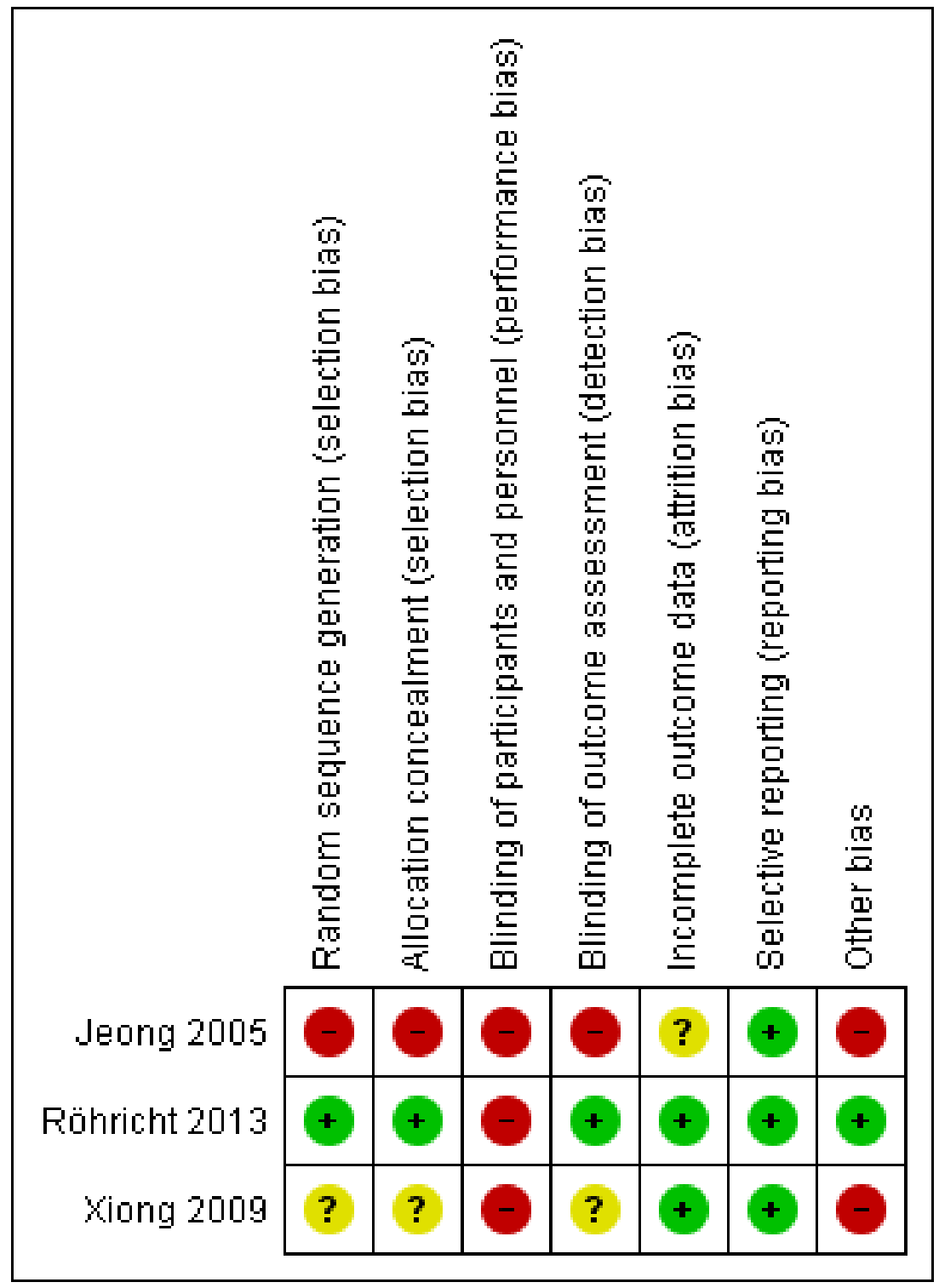




\section{Allocation}

Random sequence allocation was a low risk of bias for Röhricht 2013, for whom an independent researcher performed randomisation using a random number. Intervention and control groups had similar baseline levels of depression, as measured through the HAM-D measure (Hamilton 1960): $28.2 \pm 6.3$ and $27.2 \pm 5.4$ for the intervention and the control groups respectively, suggesting that randomisation was successful.

Jeong 2005 states that subjects were "randomly assigned to either a dance-movement group $(\mathrm{n}=20)$ or a control group $(\mathrm{n}=$ 20) by a secretary who was blind to the experimental procedures" ( 1714 ). However, no further information is given concerning the method of randomisation, or about allocation concealment. Jeong 2005 used a t-test to compare demographic data between the two groups at baseline. This revealed no differences in terms of age, height, weight or body mass index. Regarding depression however, paired t-test scores calculated as part of a repeated measures analysis of variance indicated that there were differences between the two groups. The treatment group score for the depression subscale of the SCL-90-C (Derogatis 1977) was $51.8 \pm 11.8$ pretreatment, while the score for the control group was $43.6 \pm 6.2$, These scores suggest that participants in the intervention group had much higher levels of depression than the control group at the start of the intervention. The final depression scores for the treatment and the control group were in fact very similar (46.4 \pm 10.2 treatment; and $46.1 \pm 5.7$ control), while standard deviations for the treatment group were higher than for the control group at both baseline and after 12 weeks. Given the difference in depression score between the two groups, selection bias is therefore considered to be high for Jeong 2005. However, it is also possible that this difference occurred by chance, due to the low sample size. Intervention and control groups for Xiong 2009 had similar baseline depression scored using the HAM-D measure.The authors reported no significant differences between the intervention and control group pre-treatment using a t-test; the intervention group score was: $34.43 \pm 8.93$, control $33.16 \pm 9.31$. Nevertheless, allocation bias is unclear due to a lack of information; the only information given concerning allocation is that "All patients were randomly divided into two 38-patient groups.”

\section{Blinding}

\section{Participants and personnel}

This was high risk for all studies, since it is impossible to blind either the participants or therapists to this kind of treatment. However, both Jeong 2005 and Röhricht 2013 used independent personnel to perform the randomisation, whereas Xiong 2009 does not report on this. Röhricht 2013, however, asked participants not to reveal details of their treatment until the end of the study when qualitative data were collected, thus minimising the risk that participants would be treated favourably for standard care, due to their allocation.

\section{Outcome assessment}

There were some important differences between studies in terms of blinding for outcome assessment. The HAM-D scale used by both Röhricht 2013 and Xiong 2009 is not a self-report measure, but observational by a health professional and so the question of who conducts the measure is crucial in understanding the risk of bias and overall methodological quality of the study. Only Röhricht 2013 specifically states that an independent psychiatrist, blinded to allocation, conducted these measures and patients were asked not to reveal any details of their treatment to anyone until after the post-treatment assessment (though they did reveal this at the end of the follow-up interview, which was part of the qualitative arm of the study). The detection risk is unclear for Xiong 2009 but high for Jeong 2005 since they used a self-report measure and so the person completing this by definition knew the allocation arm.

\section{Incomplete outcome data}

Attrition bias is defined as 'systematic differences between groups in withdrawals from a study' (Table 8.4a, Higgins 2011). There is a low risk for attrition bias for Xiong 2009, since there were no drop-outs. For the Röhricht 2013 study drop-out rates were five out of $16(31.25 \%)$ from the intervention group, and three out of $15(20 \%)$ from control. The attrition rate is also approximately $11 \%$ higher in the DMT group than in the control, although the odds ratio is calculated as 1.82 (95\% confidence interval (CI) $0.35,9.45)$ which is not significant. No information was available on inquiry with the authors concerning the reasons for drop-outs. The risk of bias is therefore cautiously scored as unclear. No information about drop-out rates is given in Jeong 2005, making this an unclear risk.

\section{Selective reporting}

Given the generic nature of the measure used by Jeong 2005, we considered whether there may be reporting bias arising from the results. However, it is likely that depression was intended as the primary outcome since the Beck 1961 depression inventory was used to identify the sample, confirmed by a period of clinical evaluation. None of the studies reported a published protocol, but it is evident that expected outcomes were measured. A judgement of low risk is therefore made for all studies in respect of reporting bias, as indicated in Table 8.5.d of the Cochrane Handbook for Systematic Reviews of Interventions (Higgins 2011).

Dance movement therapy for depression (Review) 


\section{Other potential sources of bias}

The other potential sources of bias considered were: outcome measure used; treatment fidelity; and level of therapist training. The outcome measure used by Jeong 2005 has been criticised as lacking specificity and sensitivity with regards to measuring depression. No explanation is given for the fact that the Beck Depression Inventory scores are not reported as an outcome measure, despite this more reliable measure having been used to identify the sample, and so this study has a high risk of bias for outcome measure. Xiong 2009 and Jeong 2005 give no information about treatment fidelity (indicating an unclear risk of bias), whereas it is clear for Röhricht 2013 that a manualised treatment was adhered to, indicating a low risk of bias for this item. For Röhricht 2013, both therapist and supervisor were qualified and experienced, again indicating a low risk of bias. The low level of training for Xiong 2009 represents a high risk of bias for therapist training. No information is given about therapist training by Jeong 2005.

\section{Effects of interventions}

See: Summary of findings for the main comparison Dance Movement Therapy (DMT) compared to standard care or waiting list control for depression

Three studies met the inclusion criteria for the review. The following planned comparisons were not possible due to a lack of data:

- DMT with other psychological therapies (e.g. psychodynamic, humanistic, cognitive behavioural (CBT) and integrative therapies)

- DMT with pharmacological interventions (e.g. antidepressants, minor tranquillisers or mood stabilisers)
- DMT with other physical interventions (e.g. dance or exercise)

- Different forms of DMT (e.g. Laban-based DMT, Chace methods of DMT or Authentic Movement)

\section{Comparison I: DMT versus no treatment (waiting list) and DMT plus standard care versus standard care}

Primary outcomes

\subsection{Level of depression}

A total of 147 people participated in three studies; 74 received DMT, while 73 received either standard care or were included in a waiting list.

The analysis of all three studies is shown diagrammatically in Figure 4 (Analysis 1.1). Our meta-analysis revealed a Standard Mean Difference (SMD) between end scores using a random effects model of -0.67 (95\% CI -1.4 to 0.05 ). Using Cohen's rule of thumb, a SMD of -0.67 is considered to be a medium effect. However, given that the CI crosses the line of no effect and into the possibility of a very small negative effect, it is not possible to state with confidence that DMT has an effect in either direction. $\mathrm{I}^{2}$ was calculated as $76 \%$, suggesting significant heterogeneity between the studies. A sensitivity analysis was performed using a fixed-effect model. This suggested a SMD of -0.73 (95\% CI -1.07 to 0.39 ). Using Cohen's rule of thumb, this suggests a large effect but the CI still crosses the line of no effect and so it remains impossible to say with any confidence whether DMT has an effect on depression in either direction.

Figure 4. Forest plot of comparison: I DMT with or without standard care vs standard care or waiting list control, outcome: I.I Depression score.

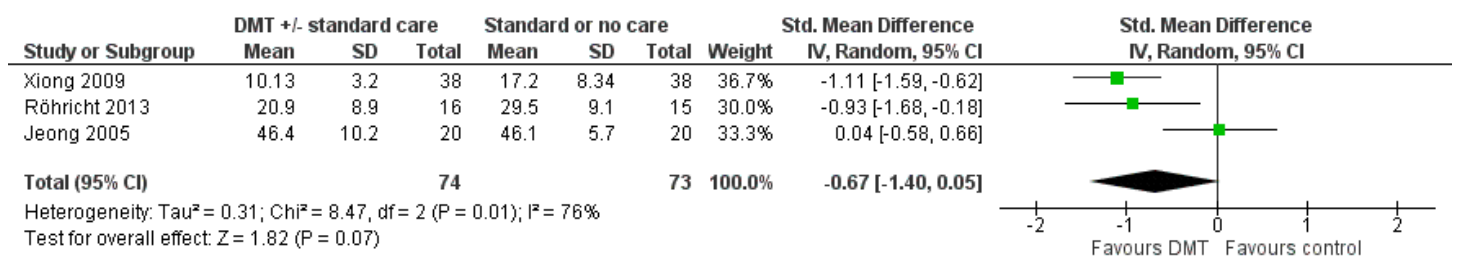

\subsection{Drop-out rates}

Complete sets of data (before and after measures) for depression levels were available for 138 people across three studies out of the initial 147 participants; 69 received DMT, while 70 received standard care. Jeong 2005 did not report on drop outs and Xiong 2009 reported that there were no drop outs. For the Röhricht 2013 study drop out rates were five out of 16 (31.25\%) from the intervention group, three out of 15 (20\%) from control. This 
suggests an $11 \%$ higher drop-out rate in the treatment group. However, the odds ratio is calculated as 1.82 (95\% CI 0.35, 9.45) which is not considered to be significant.

\section{Secondary outcomes}

\subsection{Social and occupational functioning}

Social functioning is addressed in only one of the included studies (Jeong 2005). From the 40 participants in the Jeong 2005 study (20 in the intervention and 20 in the control group), betweengroup difference in interpersonal sensitivity is reported as measured by a subscale of the SCLR-90-R (Derogatis 1977). An MD of $-6.80(95 \%$ CI -11.44 to -2.16$)$ is calculated, but given the low methodological quality of this study, limitations of the scale and small number of participants, it is not possible to draw any conclusions about the effect of DMT on social and occupational functioning.

\subsection{Quality of life}

Only one study addresses quality of life (Röhricht 2013), involving scores on the Manchester Short Assessment of Quality of Life (MANSA) test, from 22 participants post-treatment (10 DMT, 12 control). A MD of 0.30 ( $95 \%$ CI -0.60 to 1.20 ) is calculated (where a higher score indicates higher quality of life). However, since this crosses the line from positive to negative effect it is not possible to draw any conclusions about the effect of DMT on quality of life .

\subsection{Self esteem}

Similarly, only one study (Röhricht 2013) reported on self esteem, using on the Rosenberg Self Esteem scale from 21 participants post-treatment (11 DMT, 10 control). The MD between the two groups is calculated as 1.70 (95\% CI -2.36 to 5.76), where a larger score indicates higher self esteem. Given that this crosses the line from a positive effect to a negative effect, there is no evidence to suggest an effect on self esteem in either direction.

\subsection{Body image}

There was no outcome measure relating to body image in the three trials included.

\subsection{Cost-effectiveness of treatment}

No information is given about cost-effectiveness for any of the included studies.

\section{Subgroup analyses}

The only subgroup analysis that was performed was on the basis of age: there was insufficient data to perform the planned subgroup analyses on:

- group or individual;

- moving or non-moving therapist;

- length of treatment including number of sessions (session number of fewer than 12, 12 and more);

- intensity of intervention, to include frequency (weekly or less frequent, bi-weekly or more frequent); and duration of sessions (one hour or less, more than one hour);

- severity of depression at start of treatment (mild, moderate or severe, as identified by the trialist using standardised measures);

- the participant characteristic of gender (men, women or other); and

- setting (statutory and non-statutory).

\section{Subgroup analysis by age}

DMT plus standard care or no treatment versus standard care or no treatment: level of depression.

It was possible to undertake a planned subgroup analysis by age for DMT for depression plus either standard care or no treatment versus standard care or no treatment, but it was not possible to include certain age groups in this due to lack of data (over 65, or children under the age of 16). We considered the two studies of adults together (Xiong 2009 and Röhricht 2013) and the study of adolescents separately (Jeong 2005) (See Figure 5). This grouping by age accounted for the heterogeneity observed in the main analysis: it reduced the $\mathrm{I}^{2}$ statistic from $76 \%$ (for the three studies) to $0 \%$ for the two studies in adults ( $\mathrm{I}^{2}$ is not relevant for the study in adolescents as only one study was available); in other words, there was no statistical heterogeneity between these two studies as measured by the $\mathrm{I}^{2}$ statistic. The two studies of adults were homogenous in terms of the sample (age of participants) and outcome measure (HAM-D). 
Figure 5. Forest plot of comparison: I DMT vs standard care or waiting list control, outcome: I.2 Depression score sub-group analysis children vs adults.

\begin{tabular}{|c|c|c|c|c|c|c|c|c|c|}
\hline \multirow[b]{2}{*}{ Study or Subgroup } & \multicolumn{2}{|c|}{ DMT } & \multicolumn{4}{|c|}{ Standard care } & \multirow[b]{2}{*}{ Weight } & \multirow{2}{*}{$\begin{array}{l}\text { Mean Difference } \\
\text { IV, Random, } 95 \% \mathrm{Cl}\end{array}$} & \multirow{2}{*}{$\begin{array}{c}\text { Mean Difference } \\
\text { IV, Random, } 95 \% \mathrm{Cl}\end{array}$} \\
\hline & Mean & SD & Total & Mean & SD & Total & & & \\
\hline \multicolumn{10}{|l|}{ 1.2.1 children } \\
\hline $\begin{array}{l}\text { Jeong } 2005 \\
\text { Subtotal }(95 \% \mathrm{Cl})\end{array}$ & 46.4 & 10.2 & $\begin{array}{l}20 \\
20\end{array}$ & 46.1 & 5.7 & $\begin{array}{l}20 \\
20\end{array}$ & $\begin{array}{l}100.0 \% \\
\mathbf{1 0 0 . 0} \%\end{array}$ & $\begin{array}{c}0.30[-4.82,5.42] \\
\mathbf{0 . 3 0}[-4.82,5.42]\end{array}$ & \\
\hline \multicolumn{10}{|c|}{$\begin{array}{l}\text { Heterogeneity: Not applicable } \\
\text { Test for overall effect: } Z=0.11(P=0.91)\end{array}$} \\
\hline \multicolumn{10}{|l|}{ 1.2.2 adults } \\
\hline Röhricht 2013 & 20.9 & 8.9 & 16 & 29.5 & 9.1 & 15 & $16.7 \%$ & $-8.60[-14.94,-2.26]$ & \\
\hline $\begin{array}{l}\text { Xiong } 2009 \\
\text { Subtotal }(95 \% \mathrm{Cl})\end{array}$ & 10.13 & 3.2 & $\begin{array}{l}38 \\
\mathbf{5 4}\end{array}$ & 17.2 & 8.34 & $\begin{array}{l}38 \\
53\end{array}$ & $\begin{array}{r}83.3 \% \\
100.0 \%\end{array}$ & $\begin{array}{l}-7.07[-9.91,-4.23] \\
-7.33[-9.92,-4.73]\end{array}$ & \\
\hline \multicolumn{10}{|c|}{$\begin{array}{l}\text { Heterogeneity: } \text { Tau }^{2}=0.00 ; \mathrm{Chi}^{2}=0.19, \mathrm{df}=1(\mathrm{P}=0.67) ;\left.\right|^{2}=0 \% \\
\text { Test for overall effect: } Z=5.54(P<0.00001)\end{array}$} \\
\hline Test for subqroup di & erences: & $\mathrm{Chi}^{2}=$ & $=6.78$. & $d f=1(F$ & $=0.0$ & 09), $\left.\right|^{2}=$ & $85.3 \%$ & & $\begin{array}{lllcc}-20 & -10 & 0 & 10 & 20 \\
\text { Favours DMT } & \text { Favours control }\end{array}$ \\
\hline
\end{tabular}

The overall effect estimate for adults using a random-effects model was a MD between DMT plus standard care and standard care control for adults of -7.33 (95\% CI -9.92 to -4.73$)$ Analysis 1.2 . This means that the DMT group had a depression score at least 4.7 points less than the control group, and the estimates are that it could be as much as a 9.9 point difference on the HAM-D, with the central estimate of a 7.3 point difference. To establish whether this is clinically significant, the following calculation can be used: Röhricht 2013 define significant improvement as a reduction in score from baseline to post-intervention of at least $25 \%$. Xiong 2009 use a more stringent system: a reduction in score of $\geq 75 \%$ for recovery, $50 \%$ to $74 \%$ for significant effect, $25 \%$ to $49 \%$ for some improvement and $<25 \%$ for ineffective. The DMT group average baseline scores across the two adult studies was 32.58 . Taking a $25 \%$ reduction in this score as a Minimum Clinically Important Difference, we would expect therefore to see a reduction in HAM-D score of 8.15. The MD does not meet this minimum: at the outer bounds some people will have experienced a clinically important change in score (-9.92), but others will not, and some will have achieved far less than the MCID (-4.73). The result should be treated with caution, since it is based on just two studies with a total of 107 participants.

The adolescent study (Jeong 2005) was considered separately. As shown in Analysis 1.2, the difference between end scores was 0.3 (95\% CI -4.82 to 5.42 ). There is thus no significant difference between the two groups and therefore no evidence of an effect in either direction of DMT for depression in adolescents.

\section{Sensitivity analyses}

No formal sensitivity analysis was performed, due to the small number of studies included in this review. The lack of high quality evidence and the low number of studies together suggest that all results should be treated with caution. However, the planned subgroup analysis by age group co-incidentally excluded the study of lowest methodological quality.

\section{DISCUSSION}

\section{Summary of main results}

Evidence from three studies in 96 women and 51 men was inconclusive concerning any effects of DMT on depression; this evidence was of very low quality. When a planned subgroup analysis of two homogenous adult studies (51 men and 56 women) was performed (Figure 5), there was evidence of a reduction in depression for group DMT conducted over a period between 4 and 10 weeks with a total of 20 sessions and combined with standard care, as compared with standard care alone; however, this result did not meet the criteria for a Minimum Clinically Important Difference and must be treated with caution since it is based on a sub-group analysis of just two studies of moderate to low methodological quality (107 participants). It was not possible to conclude anything concerning the acceptability of DMT from drop-out rates. Effects concerning social functioning, self-esteem and quality of life were inconclusive. All results are treated with caution, due to the low quality of evidence.

\section{Overall completeness and applicability of evidence}

\section{Population}

The evidence for this review, while limited to three studies each with small sample sizes, is drawn from more than one cultural

Dance movement therapy for depression (Review) 
context; the Röhricht 2013 study was carried out in the UK while the Xiong 2009 study was conducted in China and Jeong 2005 in Korea. In terms of age groups, there is incomplete evidence concerning both upper and lower age groups, with no studies found for children under the age of 16 , or for older adults. There were, however, some marked differences in terms of age groups, setting and severity of depression between the included studies: Jeong 2005 recruited adolescents within a school population, while the other two studies recruited adults in mental health services. Xiong 2009 recruited on average a younger population than those recruited by Röhricht 2013 (Xiong 2009 mean age: 32.26, SD: 8.71; Röhricht 2013 mean age: 47.7, SD: 10.4). Participants had higher levels of depression pre-treatment in Xiong 2009 than Röhricht 2013 (Xiong 2009 mean intervention group HAM-D score: 34.43, SD 8.93; Röhricht 2013 mean intervention HAMD score: 28.2, SD: 6.3 , thus 6 points difference on the HAM-D measure between the two studies). This could be explained by the fact that the Chinese study Xiong 2009 was of inpatients, whereas the UK study Röhricht 2013 was of outpatients who might be expected to have slightly lower levels of depression.

\section{Intervention}

The applicability of the evidence in this review is compromised by the lack of unity in the way therapists are accredited around the world. For example, in China where one of the studies was located there is not, as yet, a professional association and training opportunities are concentrated in major cities like Beijing (which is not where the study was located). In Korea and the UK, where the other two studies were located, the profession is well established, though only the UK study reported on therapist qualification.

All of the studies reported outcomes for group DMT; there were none for individual or other formats (e.g. family). The intervention for two of the studies was based on Chace methods, while a third study integrated more than one approach to DMT, together with other body-based techniques. No studies reported the use of Authentic Movement.

One of the included studies, Xiong 2009, was unique to CINAHL. CINAHL is not indexed on any of the other databases searched and so this suggests that CINAHL should be included in future searches for DMT studies with all populations.

\section{Comparisons}

For this review, it was not possible to compare different approaches to DMT, or to compare DMT to other evidence based treatments.

\section{Outcomes}

In terms of the planned outcomes, complete data were only available for depression scores. Incomplete data were available for dropout rates, social and occupational functioning, quality of life and self esteem, while no data were available concerning body image or cost effectiveness. No follow-up outcome data were available. Only Röhricht 2013 presented what they describe as an ITT analysis. On our inquiries with the first author we discovered that missing data were simply excluded from the analysis. No raw data were available, and so we were unable to undertake our own im- puted measures or available case analysis. Given that genuine ITT analyses tend to bias towards no difference (because they include participants who are randomised to the treatment group but in fact receive something else) we had intended to perform a sensitivity analysis (Higgins 2011, 16.2.3); however, this was not possible due to the small number of studies. The reported drop-out rates in the Röhricht 2013 study should also be cautiously interpreted as they may be culturally influenced. In the UK, for example, patients have been encouraged in recent years to be assertive about their health choices. In the absence of further studies from around the world, however, this remains conjecture.

\section{Quality of the evidence}

Overall, the quality of evidence contributing to this review's outcomes is low to very low (see Summary of findings for the main comparison). Part of the reason for this is that the adolescent study, Jeong 2005, is of very low methodological quality. This used a selfrating outcome measure (SCL-90-R) for which depression was only a subscale, with no independent clinical measure of depression. The scale has been criticised as lacking specificity and sensitivity as a measure for depression (Choquette 1994). When several outcomes are reported, arguably one of these will be found to be positive. However, depression was an intended measure as evidenced by the selection process, which included use of a valid and reliable depression scale (Beck 1961). Other reasons for the low methodological quality of this study include insufficient reporting regarding random sequence generation or allocation concealment. Furthermore, the difference in baseline scores for depression may indicate an unsuccessful randomisation process. An independent t-test was used to compare demographic data between the two groups (and thus demonstrate similarity at baseline) but no such comparison is offered for depression data. The authors state that there was no significant effect of group but these data are not given; only group $\mathrm{x}$ time are shown in their table. While the authors did use a repeated measures of variance test, this would have been made more robust by using ANCOVA, which is deemed to have greater power in detecting any effect of certain factors (like baseline depression score) on the outcome variable when variance has been removed. Thus, if there was a significant difference between the two baseline depression scores it would be able to iron out these differences. Furthermore, no information is given by Jeong 2005 regarding therapist qualification or treatment fidelity.

The two adult studies reviewed (Xiong 2009; Röhricht 2013) included a relatively small number of participants. Only 49 participants attended the group DMT in these two studies compared to 50 participants in the control group (standard care), while neither of the them included a power calculation. For one of these studies, Xiong 2009, insufficient information was given regarding randomisation and allocation concealment. It is impossible to blind participants or therapists to the intervention, though more methodologically rigorous studies would blind allocation and as- 
sessment. Applying these criteria, both Jeong 2005 and Röhricht 2013 used independent personnel to perform the randomisation, whereas Xiong 2009 does not report on this. Röhricht 2013 also reported blinding of assessment, explicitly stating that the HAM$\mathrm{D}$ was scored by an independent psychiatrist, blinded to allocation, enhancing confidence in the results of this study. Participants were also asked not to reveal the details of their treatment to assessors. Both adult studies included a clinician rating (the HAMD), but in the Xiong 2009 study it remains unclear whether an independent assessor was used. The detection risk is thus unclear for Xiong 2009 but high for Jeong 2005 since they used a selfreport measure and so the person completing this by definition knew the allocation arm.

A further compromise to the quality of evidence lies in treatment fidelity, which is only articulated for one of the three studies included (Röhricht 2013). Linked to this, therapist qualification is associated with risk of bias: therapist qualification was low for Xiong 2009, unstated for Jeong 2005 and of a high standard for Röhricht 2013. In the Xiong 2009 study, the treatment was given by someone who had not received a full training or qualification in DMT; the results from this study as reported by the trialists must therefore be treated with considerable caution. Xiong 2009 was only included in the review due to the fact that the profession is still developing in China, and there is no register of qualified practitioners. This mirrors the situation in the UK prior to the 1990s. Researcher allegiance is unclear for all studies. These elements will be more formally assessed when the review is updated.

\section{Potential biases in the review process}

One possible area of bias is that, given the low number of published studies, some of the relevant trials may exist in the grey literature. We intended to use a funnel plot analysis to examine publication bias if there were more than 10 studies addressing a particular question. However, since only three studies met the inclusion criteria this was not possible. The review authors made extensive efforts to locate all relevant studies, using their professional networks worldwide to search for studies in progress and unpublished studies in addition to published work located through literature searches. This resulted in one study being included which would not otherwise have initially been located, due to the fact that it was unpublished at the time the original search was carried out (now published); this is the Röhricht 2013 study (which in a later search was also revealed by CCDAN). Research in DMT has developed considerably both in methodological quality and quantity over the past two decades, and it is likely therefore that new studies will emerge of relevance to this review in coming years.

Another possible source of bias lies in the definition used to identify studies of DMT. The authors made use of their professional knowledge in order to identify one trial (Röhricht 2013) that, on initial inspection, did not seem to fit the description of DMT because it claims to be testing a form of body psychotherapy (BPT).
The authors were aware of a previous published trial of BPT for schizophrenia and also had information about current developments in BPT for schizophrenia (all by the same lead author). We knew that the manual had been developed with considerable input from a dance movement therapist, and so were prepared to search specifically using appropriate terms. On reading the study, it became obvious that the treatment was also carried out and supervised by experienced and qualified dance movement therapists. We contacted the lead author direct for further details on this study. However, it is possible that other studies exist concerning BPT that would also fit our inclusion criteria. Conversely, we rejected at least one study that purported to report DMT effects but did not fit our inclusion criteria because they did not include active movement on the part of the individual with depression. The connoisseurship necessary to make judgements about whether or not the reported intervention constituted DMT was vital when considering an emerging international literature. However, this does raise the question of to what extent the included studies are comparable. The Röhricht 2013 study made use of a trained Dance Movement Therapist to deliver the treatment, whereas Xiong 2009 used a nurse with further 'counselling' training (orientation not defined), not a qualified or student Dance Movement Therapist. We decided to include Xiong 2009 because the authors presented a theoretical rationale and description of the intervention that referenced key DMT approaches. Jeong 2005 do not give any information about the therapist who carried out the treatment under investigation; however, the description clearly fits DMT as a psychotherapeutic intervention. This reflects the global situation in that in the UK, there are a number of accredited trainings and a register of DMT practitioners, whereas in some countries DMT is an emerging profession, without the benefit of full trainings or a register of practitioners. Korea does have the Korean Dance Therapy Association, while China has yet to develop a professional membership. An alternative view to the assumption that DMT should represent a homogeneous practice globally is that of cultural adaptiveness: each country may well develop a slightly different version of DMT, adapted to the populations served. Some evidence of this is contained in narrative accounts of pioneering DMT in different countries, as with Levy 1992 and Meekums 2008. Our definition of DMT is culturally biased towards the way it is practised in the UK, USA and increasingly worldwide (as evidenced in this review), but there may be other, equally valid, versions of DMT which we have not considered.

It is possible that the way in which drop-outs and missing data were treated could have impacted on the conclusions of this review. This is partly due to a lack of information from the trialists. Dropouts as reported by Röhricht 2013 may have been due to large improvements, no improvement, or not liking the intervention regardless of the impact it was having on the depression; however, this information was unavailable. According to Nelson 2010, there is a need for a best and worst case analysis regardless of the extent of drop-out from the treatment arm, since it is possible that if 
one person drops out from each arm, this could skew the data considerably: for example, the one person dropping out from the treatment arm does so because they have improved and no longer feel they need treatment, whereas the one person dropping out from the control group does so due to resentful demoralisation. Finally, while it was useful to include dance movement therapists on the research team in order to identify and discuss studies, researcher allegiance could have biased this study. This was addressed by also having a member of the team (the third author) who is a Cochrane Editor in a different group, and has no allegiance to DMT whatsoever (being a Professor of wound healing). She acted as critical friend throughout, challenging assumptions and mitigating against any biased tendency towards positive reporting.

\section{Agreements and disagreements with other studies or reviews}

A Cochrane systematic review of exercise for depression by Rimer 2012 included a subgroup analysis for type of exercise, but was limited to a comparison of aerobic, resistance, and mixed, with no examination of different types of aerobic exercise. DMT includes aerobic exercise in the form of dance exercise, with additional psychotherapeutic components as explained above in How the intervention might work. This review therefore extends the findings reported by Rimer 2012; however, the small number of trials and low quality of evidence prevent any firm conclusions concerning this particular intervention.

Findings from this review also extend previous evidence related to DMT with two key populations. The Cochrane review on DMT for schizophrenia by Ren 2013 included just one study, and so it was not possible to draw conclusions about whether or not DMT is effective with people who have schizophrenia, though moderatequality evidence was available in this one trial for a positive effect by DMT on negative symptoms of schizophrenia; these symptoms are closely connected to low mood. Bradt 2010 identified two studies with small sample sizes and judged them to be of very low methodological quality, in her Cochrane review of DMT for people with cancer. They found no evidence for an impact of DMT on psychological or mood outcomes; one study, judged to be at a high risk of bias, claimed a positive effect on quality of life and fatigue. Unlike previous Cochrane systematic reviews of DMT, this is the first time that depression has been studied as the main diagnosis rather than as secondary to either schizophrenia or cancer; however, it is not possible to draw any conclusions concerning whether or not DMT is effective with this population, and more research of high methodological quality is needed.

\section{A U THORS' CONCLUSIONS}

\section{Implications for practice}

The low number of studies, together with low quality of the evidence from them, make it difficult to draw any conclusions about the effectiveness of DMT for depression. Only one included study, Röhricht 2013, was judged to be of moderate methodological quality, with the other two of either low or very low methodological quality. The estimated effect of DMT is imprecise for both adults and adolescents, due to the low number of trials and participants, leading to wide confidence intervals. There are currently no studies with a randomised design investigating DMT for depression in either children under the age of 16 , or older adults.

\section{Implications for research}

The implications for research are considered using the EPICOT framework, as follows:

Evidence: The results concerning DMT for depression were not significant. While there is some evidence of an effect for adults, this is based on a subgroup analysis of two small studies of moderate to low methodological quality. The evidence concerning DMT for depression in adolescents is based on just one study of low methodological quality and therefore while there is no evidence of an effect in either direction this does not constitute evidence of no effect. Future research requires studies of high methodological quality that address the shortcomings of those studies reviewed here, including clear strategies for allocation concealment, blinding of assessors, and statistical measures for dealing with dropouts. Further trials of high methodological quality are required that evaluate the effects of DMT on depression in both adult and child/adolescent populations to enable us to examine the size of effect of DMT in these subgroups reliably. This should include economic analysis, and acceptability measures

Population: Future studies should focus on depression as a primary diagnostic category, with a homogenous age group; there is a need for studies of high methodological quality with both adult, older adult, child and adolescent populations. Studies are needed in a wide range of global settings.

Intervention: Only the Röhricht 2013 study used a manualised treatment, delivered by a qualified and experienced dance movement therapist. There are several approaches to DMT described in the literature and so future research should focus on defining DMT within the trial through manualised treatments. Some dance movement therapists may have objections to manualised treatments as they are seen as removing some of the key elements of the intervention, including therapist responsiveness and creativity. There is also an argument for culturally-adapted forms of DMT rather than any attempt at homogeneity which could impose a Western bias. However, it is possible to design manuals that allow for these important concerns.

Comparison: Standard care or waiting list (no treatment) were the only comparisons available. Given that DMT involves both 
exercise and music, there is a need for comparison groups that control for these effects. Comparison with other evidence-based psychological therapies (for example, CBT) would also be advantageous.

Outcome: The outcome measure used by the two adult studies was a clinical instrument (the HAM-D), which when applied by an independent assessor (as for Röhricht 2013) arguably offers a more reliable measure than self-completion scales. Researchers should consider using the same scale for future studies, with the addition of follow-up measurements. The inclusion of economic analyses and acceptability measures will make it possible to make a more realistic assessment about the practice implications.

Time stamp: All three studies included in this review were published in the previous eight years, suggesting that RCTs of DMT are still in their infancy. There is a need for more studies so that evidence can be built with contemporary relevance.

\section{ACKNOW LEDGEMENTS}

We wish to acknowledge the contribution of the CCDAN editorial team. We also wish to acknowledge the prior work undertaken by Andrea Nundy-Mala in our initial scoping study and Dr Cochavit Elefant in helping to prepare the registration of the title.

We are also very grateful to Lufia Chen and to Dr. Li Weixiao, for translation of Xiong 2009.

\section{CRG Funding Acknowledgement:}

The National Institute for Health Research (NIHR) is the largest single funder of the Cochrane Depression, Anxiety and Neurosis Group.

Disclaimer:

The views and opinions expressed herein are those of the authors and do not necessarily reflect those of the NIHR, NHS or the Department of Health.

\section{R E F E R E N C E S}

\section{References to studies included in this review}

Jeong 2005 \{published data only\}

Jeong YJ, Hong SC, Myeong SL, Park MC, Kim YK, Suh CM. Dance Movement Therapy improves emotional responses and modulates neurohormones in adolescents with mild depression. International Journal of Neuroscience 2005; 115:1711-20.

Röhricht 2013 \{published and unpublished data\} Papadopoulos NLR, Röhricht F. An investigation into the application and processes of manualised group body psychotherapy for depressive disorder in a clinical trial. Body, movement and dance in psychotherapy 2014;9(3): $167-80$.

Röhricht F, Papadopoulos N, Priebe S. An exploratory randomised controlled trial of body psychotherapy for patients with chronic depression. Personal communication 2013.

* Röhricht F, Papadopoulos N, Priebe S. An exploratory randomized controlled trial of body psychotherapy for patients with chronic depression. Journal of Affective Disorders 2013;151:85-91. [DOI: 10.1016/ j.jad.2013.05.056]

Xiong 2009 \{published data only\}

Xiong L, Li M, Li Q. Influence of dance therapy on selfefficacy and rehabilitation of patients with depression

[舞蹈治疗对抑郁症病人自我效能及康复的影响]. Chinese Nursing Research 2009;23(12A):3138-3139.

References to studies excluded from this review
Akandere 2011 \{published data only\}

Akandere M, Demir B. The effect of dance over depression. Collegium Antropologicum 2011;35(3):651-6.

Alpert 2007 \{published data only\}

Alpert PT, Miller S, Wallman H. Modified jazz dance effects on balance cognition and mood in older women. Communicating Nursing Research 2007;40:359.

Ando 2009 \{published data only\}

Ando M, Morita T, Akechi T, Ito S, Tanaka M, Ifuku Y, et al. The efficacy of mindfulness-based meditation therapy on anxiety, depression and spirituality in Japanese patients with cancer. Journal of Palliative medicine 2009;12(12):1091-4.

Anonymous 2007 \{published data only\}

Anonymous. Dance to beat depression. Working with older people 2007;11(1):8.

Astin 2003 \{published data only\} Astin JA, Berman BM, Bausell B, Lee W, Hochberg M, Forys KL. The efficacy of mindfulness meditation plus qigong movement therapy in the treatment of fibromyalgia: a randomised controlled trial. Journal of Rheumatology 2003;30(10):2257-62.

Baptista 2012 \{published data only\}

Baptista AS, Villela AL, Jones A, Natour J. Effectiveness of dance in patients with fibromyalgia: a randomized, single-blind, controlled study. Clinical and Experimental Rheumatology 2012;30(6 Suppl 74):18-23.

Belcher 2009 \{unpublished data only\} Belcher HME. Yoga Based Movement Therapy Feasibility and Efficacy Study. http://clinicaltrials.gov/ct2/show/ NCT01524172 2009. 
Birks 2007 \{published data only\}

Birks M. Benefits of salsa classes in treatment of depression. Nursing Times 2007;103(10):32-3.

Bolton 2009 \{published data only\}

Bolton P, Murray L, Bass J. School based intervention improves PTSD symptoms in children affected by political violence. Evidence-Based Mental Health 2009;12(2):47.

Bräuninger 2012 \{published and unpublished data\} * Bräuninger I. Dance movement therapy group intervention in stress treatment: A randomized controlled trial (RCT). The Arts in Psychotherapy 2012;39:443-50.

Brittle 2009 \{published data only\}

Brittle N, Patel S, Wright C, Baral S, Versfeld P, Sackley C. An exploratory cluster randomized controlled trial of group exercise on mobility and depression in care home residents. Clinical Rehabilitation 2009;23(2):146-54.

Carbonell-Baeza 2010 \{published data only\} Carbonell-Baeza A, Aparicio VA, Martins-Pereira CM, Gatto-Cardia CM, Ortega FB, Huertas FJ, et al. Efficacy of Biodanza for Treating Women with Fibromyalgia. Journal of Alternative and Complementary Medicine 2010;16(11): 1191-200.

Cross 2012 \{published data only\}

Cross K, Flores R, Butterfield J, Blackman M, Lee S. The effect of passive listening versus active observation of music and dance performances on memory recognition and mild to moderate depression in cognitively impaired older adults. Psychological Reports 2012;111(2):413-23.

Duberg 2013 \{published data only\}

Duberg A, Hagberg L, Sunvisson H, Möller M. Influencing self-rated health among adolescent girls with dance intervention: a randomized controlled trial [NCT01523561]. JAMA Pediatrics 2013;167(1):27-31. Philipsson A, Duberg A, Möller M, Hagberg L. Costutility analysis of a dance intervention for adolescent girls with internalizing problems. Cost Effectiveness and Resource Allocation 2013;11(4): No pages (internet only). [DOI: $10.1186 / 1478-7547-11-4]$

Eyigor 2009 \{published data only\}

Eyigor S, Karapolat H, Durmaz B, Ibisoglu U, Cakir S. A randomized controlled trial of Turkish folklore dance on the physical performance, balance, depression and quality of life in older women. Archives of Gerontology \& Geriatrics 2009;48(1):84-8.

\section{Gordin 1981 \{published data only\}}

Gordin RD. Effects of hypnosis, relaxation training, or music on state anxiety and stress in female athletes. Dissertation Abstracts International 1981; Vol. 42, issue 2-A:0598-9.

Haboush 2006 \{published data only\} Haboush A, Floyd M, Caron J, LaSota M, Alvarez K. Ballroom dance lessons for geriatric depression: An exploratory study. The Arts in Psychotherapy 2006;33(2): 89-97.
Hackney 2010 \{published data only\}

Hackney ME, Earhart GM. Social partnered dance for people with serious and persistent mental illness: a pilot study. Journal of Nervous and Mental Disease 2010;198(1): $76-8$.

Harden 1989 \{published data only\}

Harden JAT. Effect of movement group therapy on depression, morale and self-esteem in aged women. Unpublished PhD Dissertation, University of Texas 1989.

Hartshorn 2002 \{published data only\} Hartshorn K, Delage J, Field T, Olds L. Senior citizens benefit from movement therapy. Journal of Bodywork \& Movement Therapies 2002;6(1):55-8.

Hautzinger 1995 \{published data only\} Hautzinger M, Kleine W. Athletic participation and psychological well-being. The effects of sports on depressive symptomatology [Zur Wirkung von Sport auf depressive Symptomatik]. Zeitschrift fuer Gesundheitspsychologie 1995; 3(4):255-67.

\section{Heber 1993 \{published data only\}}

Heber L. Dance movement: a therapeutic programme for psychiatric clients. Perspectives in Psychiatric Care 1993;29 (2):22-9.

\section{Hilf 2009 \{unpublished data only\}}

Hilf Z. Efficacy of Dance Therapy in the Treatment of Somatoform Disorders [Wirksamkeit von Tanztherapie bei Somatoformer Störung]. Unpublished Diploma thesis. Faculty for Sport and Health Sciences of the Technische Universität München, Germany 2009.

Horrocks 2009 \{published data only\} Horrocks A, Naidoo J, Daykin N. 'I didn't think I'd feel like this': Evaluation of the Rock-a-Bye groups, Dance Movement Therapy for postnatal women and their infants. University of the West of England 2009.

Kaltsatou 2011 \{published data only\} Kaltsatou A, Mameletzi D, Douka S. Physical and psychological benefits of a 24-week traditional dance program in breast cancer survivors. Bodywork Movement Therapy 2011;15(2):162-167.

Karkou 2010 \{published data only\} Karkou V, Fullarton A, Scarth S. Finding a Way Out of the Labyrinth through Dance Movement Psychotherapy: Collaborative Work in a Mental Health Promotion Programme for Secondary Schools. In: Karkou V editor(s). Arts Therapies in Schools: Research and Practice. London: Jessica Kingsley, 2010:59-84.

King 2010 \{unpublished data only\} King E. Jump for joy: Irish Ceili dancing with mental health patients. Unpublished MA dissertation, Autonomous University of Barcelona, Spain 2010.

Koch 2007 \{published data only\} Koch SC, Morlinghaus K, Fuchs T. The joy dance: Specific effects of a single dance intervention on psychiatric patients with depression. Arts in Psychotherapy 2007;34(4):340-9. 
Konstantinidou 2005 \{unpublished data only\}

Konstantinidou M. Effects of DMT program in the psychosocial health of elderly. Unpublished $\mathrm{PhD}$ Thesis, University of Komotini, Greece. 2005.

Krantz 1994 \{unpublished data only\}

Krantz A. Your dissertation. E-mail correspondence 3.12.12.

* Krantz AM. Dancing out trauma: The effects of psychophysical expression on health. Dissertation Abstracts International 1994.

Lauž a 2011 \{unpublished data only\}

Lauž a S. Dance movement therapy for decreasing symptoms of depression in the patients with chronic musculoskeletal pains. Unpublished Masters Dissertation: Riga Stradins University, Latvia 2011.

Lopez-Rodriguez 2012 \{published data only\} Lopez-Rodriguez Mdel M, Castro-Sanchez AM, FernandezMartinez M, Mataran-Penarrocha GA, Rodriguez-Ferrer ME. Comparison between aquatic-biodanza and stretching for improving quality of life and pain in patients with fibromyalgia [Comparacio' n entre biodanza en medio acua' tico y stretching en la mejora de la calidad de vida y dolor en los pacientes con fibromyalgia]. Atencion primaria I Sociedad Espanola de Medicina de Familia y Comunitaria 2012;44(11):641-9.

Lopez-Rodriguez 2013 \{published data only\}

Lopez-Rodriguez MM, Fernandez-Martinez M, MataranPenarrocha GA, Rodriguez-Ferrer ME, Granados Gamez G, Aguilar Ferrandiz E. Effectiveness of aquatic biodance on sleep quality, anxiety and other symptoms in patients with fibromyalgia [Efectividad de la biodanza acua' tica sobre

la calidad del suen $\sim \mathrm{o}$, la ansiedad y otros sl ' ntomas en pacientes con fibromyalgia]. Medicina clinica 2013;141 (11):471-8.

Malkina Pykh 2012 \{published data only\} Malkina Pykh IG. Effectiveness of rhythmic movement therapy for disordered eating behaviors and obesity. Spanish Journal of Psychology 2012;15(3):1371-87.

Mannheim 2013 \{published data only\}

Mannheim EG, Helmes A, Weis J [German]. . 2013, 20 (1):33-41. doi: 10.1159/000346617. Dance/movement therapy in oncological rehabilitation [Tanztherapie in der stationären onkologischen Rehabilitation]. Research in Complementary Medicine [Forschende Komplementarmedizin] 2013;20(1):33-41. [DOI: 10.1159/000346617]

Martin 2013 \{published data only\}

Martin S, Martin G, Lequertier B, Swannell S, Follent A, Choe F. Voice movement therapy: Evaluation of a groupbased expressive arts therapy for nonsuicidal self-injury in young adults. Music and Medicine 2013;5(1):31-8.

Osteras 2012 \{published data only\}

Osteras H, Osteras B, Torstensen TA. Medical exercise therapy, and not arthroscopic surgery, resulted in decreased depression and anxiety in patients with degenerative meniscus injury. Journal of Bodywork and Movement Therapies 2012;16(4):456-63.

Payne 2010 \{published data only\}

Payne H, Stott D. Change in the moving bodymind: Quantitative results from a pilot study on the use of the BodyMind approach (BMA) to psychotherapeutic group work with patients with medically unexplained symptoms (MUSs). Counselling \& Psychotherapy Research (CPR) 2010; 10(4):295-306.

Pinniger 2012 \{published data only\}

Pinniger R, Brown RF, Thorsteinsson EB, McKinley P. Argentine tango dance compared to mindfulness meditation and a waiting-list control: A randomised trial for treating depression. Complementary therapies in medicine 2012;20 (6):377-84.

Pinniger 2013a \{published data only\} Pinniger R, Brown RF, Thorsteinsson EB, McKinley P. Tango programme for individuals with age-related macular degeneration. British Journal of Visual Impairment 2013;31 (1):47-59.

Pinniger 2013b \{published data only\} Pinniger R, Thorsteinsson EB, Brown RF, McKinley P. Intensive tango dance program for people with self-referred affective symptoms. Music and Medicine 2013;5(1):15-22.

\section{Price 2004 \{published data only\}}

Price C. Body-oriented therapy in sexual abuse recovery: A pilot-test comparison. Journal of Bodywork and Movement Therapies 2006;10(1):58-64.

Price C. Characteristics of women seeking body-oriented therapy as an adjunct to psychotherapy during recovery from childhood sexual abuse. Journal of Bodywork and Movement Therapies 2004;8(1):35-42.

\section{Rasa 2011 \{unpublished data only\}}

Rasa I. Late maturity, depression, dance and movement therapy. Masters dissertation, Riga Stadins University 2011.

Reichhart 2010 \{published data only\}

Reichhart 2014. Effectiveness of a psychosomatic day hospital treatment for the elderly: A naturalistic longitudinal study with waiting time before treatment as control condition. Journal of Psychosomatic Research 2014;76(2): 121-126.

Reichhart C, Steinlein C, Soellner W. The Psychosomatic Day Hospital for the elderly (PDH 55+) - A four year review [conference abstract - abstracts from the 13th Annual Meeting of the European Association for ConsultationLiaison Psychiatry and Psychosomatics, EACLPP, 28th European Conference on Psychosomatic Research, ECPR Innsbruck Austria]. Journal of Psychosomatic Research 2010; 68(6):657.

Reinemann 1998 \{unpublished data only\}

Reinemann D. ROM dance: a treatment for symptoms of depression and anxiety in adults with mental retardation. EdD dissertation, Northern Illinois University 1998.

\section{Selman 2012 \{published data only\}}

Selman LE, Williams J, Simms V. A mixed methods evaluation of complementary therapy services in palliative 
care: yoga and dance therapy. European Journal of Cancer Care 2012;21(1):87-97.

\section{Smith 1998 \{published data only\}}

Smith JL, Noon J. Objective measurement of mood change induced by contemporary music. Journal of Psychiatric Mental Health Nursing 1998;5(5):403-8.

Stewart 1994 \{published data only\} Stewart NJ, McMullen LM, Rubin LD. Movement therapy with depressed inpatients: a randomized multiple single case design. Archives of Psychiatric Nursing 1994;8(1):22-9.

Stötter 2013 \{published data only\}

Stötter A, Mitsche M, Endler PC, Oleksy P, Kamenschek D, Mosgoeller W, et al. Mindfulness-based touch therapy and mindfulness practice in persons with moderate depression. Body, movement and dance in psychotherapy 2013;8(3): 183-98.

Vanková 2008 \{published data only\}

Vanková H, Holmerova I, Andel R, Veleta P, Janeckova H. Functional status and depressive symptoms among older adults from residential care facilities in the Czech republic. International Journal of Geriatric Psychiatry 2008;23(5): 466-71.

\section{Yang 2009 \{published data only\}}

Yang TT, Hsiao FH, Wang KC, Ng SM, Ho RT, Chan CL, et al. The effect of psychotherapy added to pharmacotherapy on cortisol responses in outpatients with major depressive disorder. Journal of Nervous and Mental Disease 2009;197(6):401-6.

Zemite 2011 \{unpublished data only\}

Zemite SS. Dance movement therapy for reducing depression symptoms of women prisoners. Masters dissertation, Riga Stradins University, Latvia 2011.

\section{References to ongoing studies}

Joseph 2014 \{unpublished data only\}

Joseph J, Karkou V. An investigation into the practice of Dance Movement Psychotherapy with adolescents within the UK. Unpublished PhD Proposal: Edge Hill University, Ormskirk, UK 2014.

\section{Additional references}

\section{Abbass 2006}

Abbass AA, Hancock JT, Henderson J, Kisely S. Shortterm psychodynamic psychotherapies for common mental disorders. Cochrane Database of Systematic Reviews 2006, Issue 4. [DOI: 10.1002/14651858.CD004687.pub3]

\section{ADMP UK 2015}

Association for Dance Movement Psychotherapy UK (ADMP UK). What is Dance Movement Psychotherapy?. http://www.admt.org.uk/dance-movement-psychotherapy/ what-is-dance-movement-psychotherapy/ c.2015 Accessed: 17 February 2015

\section{Antonuccio 1997}

Antonuccio DO, Michael T, Danton WG. A costeffectiveness analysis of cognitive behavior therapy and fluoxetine (prozac) in the treatment of depression. Behavior Therapy 1997;28(2):187-210.

APA 2000

American Psychiatric Association. DSMIV-TR: Diagnostic and Statistical Manual of Mental Disorders. Arlington, Virginia: American Psychiatric Association, July 2000.

\section{Arroll 2009}

Arroll B, Elley CR, Fishman T, Goodyear-Smith FA, Kenealy T, Blashki G, et al. Antidepressants versus placebo for depression in primary care. Cochrane Database of Systematic Reviews 2009, Issue 3. [DOI: 10.1002/ 14651858.CD007954]

\section{Bartenieff 1980}

Bartenieff I, Lewis D. Body Movement: Coping with the Environment. New York: Gordon and Breach Science Publishers, 1980.

Beck 1961

Beck AT, Ward CH, Mendelson M, Mock J, Erbaugh J. An inventory for measuring depression. Archives of General Psychiatry 1961;4(6):561-71.

Berrol 2006

Berrol C. Neuroscience meets dance/movement therapy: Mirror neurons, the therapeutic process and empathy. The Arts in Psychotherapy 2006;33:302-15.

Bradt 2010

Bradt J, Dileo C. Dance movement therapy for improving psychological and physical outcomes in cancer patients. Cochrane Database of Systematic Reviews 2010, Issue 12. [DOI: 10.1002/14651858.CD007103]

\section{Brooks 1989}

Brooks D, Stark A. The effects of dance/movement therapy on affect: A pilot study. American Journal of Dance Therapy 1989;11:101-12.

\section{Cash 2002}

Cash T, Fleming E. The impact of body-image experiences: development of the body image quality of life inventory. International Journal of Eating Disorders 2002;31:455-60.

\section{Chaiklin 1986}

Chaiklin S, Schmais D. The Chace Approach to Dance Therapy. In: Lewis P editor(s). Theoretical Approaches in Dance/Movement Therapy. Vol. 1, Iowa: Kendall/Hunt, 1986:17-36.

\section{Choquette 1994}

Choquette K A. Assessing depression in alcoholics with the BDI, SCL-90R, and DIS criteria. Journal of Substance Abuse 1994;6(3):295-304.

\section{Churchill 2010a}

Churchill R, Moore THM, Caldwell D, Davies P, Jones H, Furukawa TA, et al. Cognitive behavioural therapies versus other psychological therapies for depression. Cochrane Database of Systematic Reviews 2010, Issue 9. [DOI: 10.1002/14651858.CD008698]

\section{Churchill 2010b}

Churchill R, Moore THM, Davies P, Caldwell D, Jones $\mathrm{H}$, Lewis $\mathrm{G}$, et al. Psychodynamic therapies versus other 
psychological therapies for depression. Cochrane Database of Systematic Reviews 2010, Issue 9. [DOI: 10.1002/ 14651858.CD008706]

\section{Cruz 1998}

Cruz RF, Sabers DL. Dance/movement therapy is more effective than previously reported. The Arts in Psychotherapy 1998;25(2):101-4.

\section{Dennis 2007a}

Dennis C-L, Hodnett ED. Psychosocial and psychological interventions for treating postpartum depression. Cochrane Database of Systematic Reviews 2007, Issue 4. [DOI: 10.1002/14651858.CD006116.pub2]

\section{Dennis 2007b}

Dennis C-L, Ross LE, Grigoriadis S. Psychosocial and psychological interventions for treating antenatal depression. Cochrane Database of Systematic Reviews 2007, Issue 3. [DOI: 10.1002/14651858.CD006309.pub2]

\section{Derogatis 1977}

Derogatis LR. SCL-90-R Manual 1. Baltimore: John Hopkins University School of Medicine 1977.

\section{Dibbell-Hope 2000}

Dibbell-Hope S. The use of dance/movement therapy in psychological adaptation to breast cancer. The Arts in Psychotherapy 2000;27:51-68.

\section{Dosamantes-Alperson 1981}

Dosamantes-Alperson E. Experiencing in movement therapy. American Journal of Dance Therapy 1981;4(2): 33-44.

\section{Ehrhardt 1989}

Ehrhardt BT, Hearn MB, Novak C. Outpatient clients' attitudes towards healing processes in dance therapy. American Journal of Dance Therapy 1989;11(1):39-60.

\section{Gazzola 2006}

Gazzola V, Aziz-Zadeh L, Keysers C. Empathy and the somatotopic auditory mirror system in humans. Current Biology 2006;16:1824-9.

\section{Gibbs 2005}

Gibbs R W. Embodiment and Cognitive Science. New York: Cambridge University Press, 2005.

\section{Hamilton 1960}

Hamilton M. A rating scale for depression. Journal of Neurology, Neurosurgery, and Psychiatry 1960;23:56-62.

\section{Heimbeck 2011}

Heimbeck A, Gerd H. Movement therapy and depression evaluation study of a disorder-oriented and an unspecific movement therapeutic support in a clinical setting. Psychotherapie Psychosomatik Medizinische Psychologie May 2011;61(5):200-7.

Henken 2007

Henken T, Huibers MJ, Churchill R, Restifo KK, Roelofs JJ. Family therapy for depression. Cochrane Database of Systematic Reviews 2007, Issue 3. [DOI: 10.1002/ 14651858.CD006728]

\section{Higgins 2002}

Higgins JPT. Quantifying heterogeneity in a meta-analysis. Statistics in Medicine 2009;21:1539-58.

\section{Higgins 2011}

Higgins JPT, Green S (editors). Cochrane Handbook for Systematic Reviews of Interventions Version 5.1.0 [updated March 2011]. The Cochrane Collaboration, 2008. Available from www.cochrane-handbook.org.

\section{Hunot 2010}

Hunot V, Moore THM, Caldwell D, Davies P, Jones H, Furukawa TA, et al. Cognitive behavioural therapies versus treatment as usual for depression. Cochrane Database of Systematic Reviews 2010, Issue 9. [DOI: 10.1002/ 14651858.CD008699]

\section{Karkou 2006}

Karkou V, Sanderson V. Arts Therapies: A Research-Based Map of the Field. Edinburgh: Elsevier, 2006.

\section{Koch 2012}

Koch SC, Mehl L, Sobanski E, Sieber M, Fuchs T. Mirroring in movement: Dance therapy improves social competence, body-awareness, self-other distinction and well-being in young adults with Autism spectrum disorder. Unpublished manuscript 2012.

\section{Koch 2014}

Koch S, Kunz T, Lykou S, Cruz S. Effects of Dance Movement Therapy and Dance onHealth-Related Psychological Outcomes: A Meta-Analysis. The Arts in Psychotherapy 2014;41(1):46-64.

\section{Koch submitted}

Koch, S, Jünger J, Kelbel J, Kolter A, Sattel H, Fuchs T. (Dis-)Embodiment in Schizophrenia: Effects of Mirroring on Self-Experience, Empathy and Well-Being. In: Karkou V, Oliver, Lykouris S editor(s). The Oxford Handbook for Dance and Wellbeing. New York: Oxford University Press, (to be published 2016).

\section{Laban 1975}

Laban R. Modern Educational Dance. London: MacDonald and Evans, 1975.

Levy 1992

Levy F. Dancelmovement therapy: a healing art. Reston, VA: American Alliance for Health, Physical Education, Recreation and Dance, 1992.

\section{Mala 2012}

Mala AS, Karkou V, Meekums B. Dance/Movement Therapy (D/MT) for depression: A scoping review. The Arts in Psychotherapy February 2012;39(1):287-95.

\section{Mannheim 2006}

Mannheim E, Weis J. Dance/movement therapy with cancer patients: evaluation of process and outcome parameters. In: Koch SC, Brauninger I editor(s). Advances in Dancel Movement Therapy. Theoretical Perspectives and Empirical Findings. Berlin: Logos Verlag, 2006:61-72. 


\section{Maratos 2008}

Maratos A, Gold C, Wang X, Crawford M. Music therapy for depression. Cochrane Database of Systematic Reviews 2008, Issue 1. [DOI: 10.1002/14651858.CD004517.pub2]

Meekums 1991

Meekums B. Dance movement therapy with mothers and young children at risk of abuse. The Arts in Psychotherapy 1991;18(3):223-30.

Meekums 2002

Meekums B. Dance Movement Therapy. London: Sage, 2002.

Meekums 2008

Meekums B. Pioneering dance movement therapy in Britain: results of narrative research. The Arts in Psychotherapy 2008; 35(2):99-106.

Meekums 2012

Meekums B. Kinesthetic empathy and movement metaphor in Dance Movement Psychotherapy.. In: D Reynolds, $\mathrm{M}$ Reason editor(s). Kinaesthetic empathy in creative and cultural practices. Bristol: Intellect Publishing, 2012:51-65.

Nelson 2010

Nelson A, Dumville J, Torgerson D. Experimental research. In: K Gerrish, A Lacey editor(s). The Research Process in Nursing. 6. Chichester: Wiley-Blackwell, 2010:199-215.

\section{NICE 2010}

National Collaborating Centre for Mental Health. Depression: the NICE guideline on the treatment and management of depression in adults (updated version). National Institute for Health and Clinical Excellence 2010.

\section{Niedenthal 2006}

Niedenthal P M, Krauth-Gruber S, Ric F. Psychology of Emotion: Interpersonal, Experiential and Cognitive Approaches. new York and Hove: Psychology Press, Taylor and Francis Group., 2006.

\section{Norcross 2011}

Norcross JC, Wampold BE. What works for whom: Tailoring psychotherapy to the person. Journal of Clinical Psychology: In Session 2011;67:127-32.

\section{Pampallona 2002}

Pampallona S, Bollini P, Tibaldi G, Kupelnick B, Munizza C. Patient adherence in the treatment of depression. British Journal of Psychiatry 2002;180:104-9.

Priebe 1999

Priebe S, Huxley P, Knight S, Evans S. Application and Results of the Manchester Short Assessment of Quality of Life (MANSA). International Journal of Social Psychiatry 1999; 45(1):7-12.

Ren 2013

Ren J, Xia J. Dance therapy for schizophrenia. Cochrane Database of Systematic Reviews 2013, Issue 10. [DOI: 10.1002/14651858.CD006868.pub3]

\section{RevMan 2012}

The Nordic Cochrane Centre, The Cochrane Collaboration. Review Manager (RevMan). 5.2. Copenhagen: The Nordic Cochrane Centre, The Cochrane Collaboration, 2012.

\section{Rimer 2012}

Rimer J, Dwan K, Lawlor DA, Greig CA, McMurdo M, Morley W, Mead GE. Exercise for depression. Cochrane Database of Systematic Reviews 2012, Issue 7. [DOI: 10.1002/14651858.CD004366.pub5]

Ritter 1996

Ritter M, Low KG. Effects of Dance/Movement Therapy: a meta-analysis. The Arts in Psychotherapy 1996;23:249-60.

\section{Rizzolatti 1996}

Rizzolatti G, Fadiga L, Gallese V, Fogassi L. Premotor cortex and the recognition of motor actions. Cognitive Brain Research 1996;3:131-41.

\section{Rosenberg 1965}

Rosenberg M. Society and the adolescent self-image.

Princeton, NJ: Princeton University Press, 1965.

\section{Röhricht 2006}

Röhricht F, Priebe S. Effect of body-oriented psychological therapy on negative symptoms in schizophrenia: a randomized controlled trial. Psychological Medicine 2006;36 (5):669-78.

Scheflen 1964

Scheflen A. The significance of posture in communication systems. Psychiatry 1964;27:316-24.

\section{Schmais 1985}

Schmais, C. Healing Processes in Group Dance Therapy. American Journal of Dance Therapy 1985;8:17-36.

Scott 2003

Scott J, Dickey B. Editorial: global burden of depression: the intersection of culture and medicine. British Journal of Psychiatry 2003;183:92-4.

Tyrer 2005

Tyrer P, Nur U, Crawford M, Karlsen S, McLean C, Rao $\mathrm{B}$, et al. The Social Functioning Questionnaire: a rapid and robust measure of perceived functioning. International Journal of Social Psychiatry 2005;51:265-75.

Vos 2005

Vos T, Corry J, Haby MM, Carter R, Andrews G. Costeffectiveness of cognitive-behavioural therapy and drug interventions for major depression. Australian and New Zealand Journal of Psychiatry 2005;39(8):683-92.

\section{Whitehouse 1979}

Whitehouse M. CG Jung and dance-therapy: two major principles. In: Bernstein P L editor(s). Eight Theoretical Approaches in Dance/Movement Therapy. Vol. 1, Iowa: Kendall/Hunt, 1979.

Whitehouse 2000

Whitehouse M S. The Tao of the Body. In: Pallaro P editor (s). Authentic Movement: Essays by Mary Stacks Whitehouse, Janet Adler and Joan Chodorow (2ndedition). London: Jessica Kingsley. 2nd Edition. London: Jessica Kingsley, 2000.

\section{WHO 2004}

World Health Organization (WHO). The World Health Organization Quality of Life instrument (WHOQOL)- 
BREF. http://www.who.int/substance abuse/research tools/ whoqolbref/en/. Geneva: WHO, 2004.

\section{WHO 2010a}

World Health Organization. Depression. http:// www.who.int/mental ' health/management/depression/ definition/en/ Accessed 14.12.2010.

\section{WHO 2010b}

World Health Organization. The ICD-10 Classification of Mental and Behavioural Disorders. World Health Organization, 2010.

\section{WHO 2012}

WHO. Depression: Fact sheet N³69. http://www.who.int/ mediacentre/factsheets/fs369/en/index.html October 2012.

Williams 2002

Williams JW, Hitchock NP, Cordes JA, Ramirez G, Pignone
M. Is this patient clinically depressed?. JAMA 2002;287(9): $1160-70$.

\section{Wilson 2008}

Wilson K, Mottram PG, Vassilas C. Psychotherapeutic treatments for older depressed people. Cochrane Database of Systematic Reviews 2008, Issue 1. [DOI: 10.1002/ 14651858.CD004853.pub2]

\section{Winters 2008}

Winters AF. Emotion, Embodiment, and Mirror Neurons in Dance/Movement Therapy: A Connection Across Disciplines. American Journal of Dance Therapy 2008;30(2): 84-105.

\section{Yalom 2005}

Yalom I D, Leszcz M. Theory and Practice of Group

Psychotherapy. 5th Edition. New York: Basic Books, 2005.

* Indicates the major publication for the study 


\title{
CHARACTERISTICS OF STUDIES
}

\section{Characteristics of included studies [ordered by study ID]}

\author{
Jeong 2005
}

Methods

Participants
An RCT of DMT versus waiting list control measuring depression and interpersonal sensitivity

40 girls (mean age 16) in middle school, all of whom had completed Beck's Depression Inventory and been found to have depression over a 4 week pre-treatment assessment. Treatment group $\mathrm{n}=20$, waiting list control $\mathrm{n}=20$

Inclusion/exclusion criteria used in the study:

(a) no past or present diagnosis of psychiatric or internal illness;

(b) no neuroendocrine disorders;

(c) no history of regular exercise within the past six months;

(d) not using prescription medication or any other therapeutic treatment for depression;

(e) no habitual smoking or drinking; and

(f) parental permission to participate.
The treatment group participated in a 45-min DMT session 3 times a week for 12 weeks. No information is given about the level of training of the individual who conducted the therapy, but the description of treatment is recognisable as DMT, with a well referenced theoretical rationale

The DMT sessions were designed around four major themes:

(a) awareness of the body, the room, and the group;

(b) movement expressions and symbolic quality of movement;

(c) movement, feeling, images, and words; and

(d) differentiation and integration of feelings.

Each of these themes included various subthemes:

i. setting limits and outer, inner, and personal space;

ii. body language, the reflecting process, polarity, and inward and outward expression;

iii. playing, drawing, and verbalisation; and

iv. the inner sense, quality of movement, and expression of feelings

The subjects in the control group were invited to participate in a similar programme after the end of the study
Outcomes
All outcomes shown are for the post-intervention scores

\section{Primary outcome}

The primary outcome measure used that provided scores for emotional distress was the Symptom Check List-90-Revision (SCL-90-R) (Derogatis 1977). This measure includes a subscale for depression (13 items, each with a maximum score of 4 ). The measure was used before and after the intervention with both the treatment and the waiting list control groups. Raw scores were converted to a $\mathrm{T}$ score, in order to compare with a nonpatient population in Korea; the scores presented do not therefore reflect the maximum possible raw score of 52 . No follow up was reported

Treatment post mean: 46.4; SD: \pm 10.2

Control post mean: 46.1 ; SD: \pm 5.7

\section{Secondary outcome}

Interpersonal sensitivity, measured by another subscale of the SCL-90-R (9 items, each 
with a maximum score of 4). Given that these measurements were converted to a $\mathrm{T}$ score, the figures presented below do not reflect the maximum possible raw score of 36

Treatment post mean: 44.3; SD: 8.2

Control post mean: 51.1 ; SD: \pm 6.7

Notes

Risk of bias

Bias

Authors' judgement

Other subscales included in this outcome measure were: somatisation, obsessive-compulsive, anxiety, hostility, phobic anxiety, paranoid ideation, and psychoticism. Global scores in the form of global index, positive symptoms and positive symptoms distress index were also calculated

It is not clear why Beck's Depression Inventory that was initially used to identify participants for the study was then dropped for the more generic outcome measure of SCL90-R

Scores from the subscale of depression before the intervention took place showed that the treatment group had much higher levels of depression than the control group

\section{Support for judgement}

Random sequence generation (selection High risk bias)
Participants were "randomly assigned to either a dance-movement group $(\mathrm{n}=20)$ or a control group $(\mathrm{n}=20)$ by a secretary who was blind to the experimental procedures". No further information re. randomisation method is given. F values were calculated through a repeated measures analysis of variance; covariance was not considered. Since the statistical test used (repeated measures analysis of variance) did not accommodate sufficiently for uneven scores at baseline as for example ANCOVA does, high risk in the results from this study needs to be assumed

Allocation concealment (selection bias) High risk
Subjects were "randomly assigned to either a dance-movement group $(\mathrm{n}=20)$ or a control group $(n=20)$ by a secretary who was blind to the experimental procedures" (p1714). No further information is given concerning the method of randomisation, or about allocation concealment, but the mean scores for depression prior to the intervention were significantly different, thus leading the review authors to question the success of the randomisation process in obtaining groups with a similar prognosis. This indicates potential selection bias, though the difference could also have occurred by chance due to the low 
sample size

\begin{tabular}{|c|c|c|}
\hline $\begin{array}{l}\text { Blinding of participants and personnel } \\
\text { (performance bias) } \\
\text { All outcomes }\end{array}$ & High risk & $\begin{array}{l}\text { It is not possible to blind participants for } \\
\text { this kind of activity and so this item must } \\
\text { be considered high risk. Random sequence } \\
\text { allocation and allocation concealment are } \\
\text { both unclear }\end{array}$ \\
\hline
\end{tabular}

Blinding of outcome assessment (detection High risk

The outcome measure is a self-report tool, bias) and so this is scored as high risk

All outcomes

Incomplete outcome data (attrition bias) Unclear risk All outcomes

No information is given about any drop-

All outcomes

Selective reporting (reporting bias) Low risk
outs.

Selective reporting (reporting bias) Low risk

The protocol is not available, but all expected outcomes are reported (Higgins 2011, Section 8.5.c).

Other bias

High risk

No suggestion that there are any risks associated with design or reputation, but the outcome measure used has been criticised for lack of specificity and sensitivity with regards to measuring depression. No explanation is given for the fact that Beck's Depression Inventory scores are not reported as an outcome measure, despite this more reliable measure having been used to identify the sample. No information is given regarding the level of therapist training or treatment fidelity

Röhricht 2013

Methods A cross-over RCT including Body Psychotherapy (BPT) as the intervention and a waiting group as the control

Participants

31 adults, both male and female. Referred through community mental health team Inclusion criteria:

- Outpatients aged 18- to 65 with a DSM-IV diagnosis of non-bipolar, nonpsychotic moderate to severe recurrent depressive disorder or chronic affective disorder (dysthymia);

- A total score of $\geq 20$ on the 21-item Hamilton Rating Scale for Depression (HAM-D);

- Duration of the current episode of depression of $>2$ years (DSM-IV criterion for chronic disorder).

Exclusion criteria:

- Psycho-organic disorder;

- Substance misuse as primary diagnosis; 
Röhricht 2013 (Continued)

- Insufficient command of English to fill in the scales and participate in the groups;

- Acute suicidal ideation or psychotic symptoms.

15 people were randomised to waiting group (7 women and 8 men)

16 people were randomised to intervention ( 6 women and 10 men)

Interventions

All participants in both study arms were offered BPT, either immediately or after a 12week waiting period, in addition to Standard Care.

Standard Care: ongoing antidepressant medication and outpatient clinical management Intervention: Group size limited to 8 participants in each group. 20 sessions of $90 \mathrm{~min}$ each over 10 weeks.

Body Psychotherapy in Chronic Depression (BPT-CD)

BPT was administered as a manualised group therapy, specifically designed to address core symptoms of depression. The treatment was delivered by an experienced Dance Movement Therapist

Outcomes

All outcomes shown are for the post-intervention scores

\section{Primary outcome}

The primary outcome measure was the level of depressive symptoms as assessed on the 21-item Hamilton Rating Scale for Depression (HAM-D) (Hamilton 1960).

Statistical analysis for HAM-D scores: for $\mathrm{N}=31$, ANCOVAS adjusted for baseline score ( $\mathrm{N}$ shown in brackets is number available at post-treatment measure):

BPT group mean: 20.9; SD: $8.9(\mathrm{n}=11)$

Waiting list control mean: 29.5; SD: $9.1(\mathrm{n}=12)$

Secondary outcomes

Quality of life

The Manchester Short Assessment of Quality of Life (MANSA; Priebe 1999) was used to assess quality of life (providing a mean score of satisfaction ratings in 12 life domains, each ranging on a Likert scale of 1 = "could not be worse" to 7 = "could not be better"), computed into an average mean score across all 12 domains

MANSA (mean across 12 domains)

BPT group mean: 3.2; SD: $1.2(\mathrm{n}=10)$

Waiting list control mean: 2.9; SD: $0.9(\mathrm{n}=12)$

Self esteem

Self esteem was rated on the Rosenberg Self-Esteem Scale (Rosenberg 1965). The scale ranges from 0 to 30 . Scores between 15 and 25 are within normal range; scores below 15 suggest low self esteem

Rosenberg Self Esteem total:

BPT group: mean: 11.6; SD: $5.1(\mathrm{n}=11)$;

Waiting list control : mean: 9.9; SD: $4.4(\mathrm{n}=10)$

Notes

The therapists providing treatment in the study were otherwise not involved in the participants' care. A part-time experienced dance movement therapist conducted BPT following a manual training. The group therapy was supervised by a senior therapist in order to control for adherence to the given treatment manual (on the basis of written records of each session) and to provide clinical supervision. BPT as it is described is indistinguishable from DMT in the opinion of the review authors

This is a cross-over trial and so for the purposes of this review only the data prior to cross-over are included and not their second table which includes outcome data for

Dance movement therapy for depression (Review) 
Röhricht 2013 (Continued)

both groups. Follow-up communication with the authors clarified that the sample was normally distributed and as such the use of a parametric test such as ANCOVA was justified. They also stated that there were no known adverse effects of the intervention

\section{Risk of bias}

\begin{tabular}{|c|c|c|}
\hline Bias & Authors' judgement & Support for judgement \\
\hline $\begin{array}{l}\text { Random sequence generation (selection } \\
\text { bias) }\end{array}$ & Low risk & $\begin{array}{l}\text { Independent researcher performed ran- } \\
\text { domisation using a random number }\end{array}$ \\
\hline
\end{tabular}

Allocation concealment (selection bias) Low risk

An independent researcher performed randomisation using a random number. Participants were also asked not to reveal details of their treatment during assessments

Blinding of participants and personnel High risk (performance bias)

All outcomes

It is not possible to blind participants for this kind of activity and so this item must be considered high risk. As an added precaution, participants were also asked not to reveal details of their treatment and so standard care could not be affected by knowledge of who was in which group

Blinding of outcome assessment (detection Low risk bias)

All outcomes

Incomplete outcome data (attrition bias) Low risk All outcomes
Assessments were performed by an independent psychiatrist who was blinded to allocation, and patients were asked not to reveal any details of their treatment to anyone until after the post-treatment assessment though they did reveal this at the end of the follow-up interview (qualitative arm)

Information is given about how missing data were calculated. The study drop out rate was $20 \%$ in the control group and $31 \%$ in the intervention group, hence there was possibility of attrition bias but the odds ratio is calculated as $1.82(95 \%$ CI $0.35,9$. $45)$ which is not significant. Moreover, the authors on inquiry reported no adverse effects of DMT, though the precise reasons for drop-outs were unknown

Selective reporting (reporting bias) Low risk
The protocol is not available, but all expected outcomes are reported (Higgins 2011, Section 8.5.c)

Dance movement therapy for depression (Review) 
Röhricht 2013 (Continued)

Other bias

Low risk
No suggestion that there are any risks associated with design or reputation, therapists were highly trained, a valid and reliable scale was used, and treatment fidelity was assured

\section{Xiong 2009}

Methods
Two-armed randomised controlled trial, DMT plus standard care versus control group being standard care (routine medication and psychological support nursing), using a standardised test of depression

Setting: China, urban, hospital.

76 patients ( 33 males $\& 43$ females), mean age $32.26 \pm 8.71$ yrs

Inclusion criteria:

1. Fits CCMD-3 (Chinese Classification and Diagnostic Criteria of Disorders) diagnostic criteria for depression;

2. Joining the study voluntarily with informed consent and is willing to make improvement;

3. Able to attend all sessions.

Exclusion criteria:

1. Difficulties with verbal communication;

2. Serious physical illness;

3. Having other serious mental disorders (e.g. schizophrenia).

38 people were randomised to the standard care group ( 21 women and 17 men) 38 people were randomised to intervention ( 22 women and 16 men)

Group DMT informed by Chace methods, with 8 to 9 people in each group. Four-phase session included: warm-up; body extension (to connect with psychological function); creative section (to include connection with other group members and expression of inner states); relationship experience. The therapy was conducted by a qualified rehabilitation nurse who had also received further professional training (the national secondary qualification of psychological counselling)

The treatment lasted for 4 weeks, 5 sessions per week (Monday to Friday), 2 hours for each session, over a 4 week period. All received standard care

Control group was standard care, which consisted of medication and nursing psychological support

Outcomes

All outcomes shown are for the post-intervention scores.

Primary outcome measure: 24-item Hamilton Rating Scale for Depression (HAM-D) No other measurements noted and no follow-up data was reported beyond the end of treatment

\section{Continuous outcome:}

HAM-D at 4 weeks (end of treatment):

Intervention: mean: 10.13 ; SD: $\pm 3.20(\mathrm{n}=38)$

Control: mean 17.20; SD: $\pm 8.34(\mathrm{n}=38)$

Dichotomous outcome:

Number of people with remission or improvement at end of trial 


\begin{tabular}{|c|c|c|}
\hline & \multicolumn{2}{|c|}{$\begin{array}{l}\text { Remission (defined as } \geq 75 \% \text { reduction on HAMD); } \\
\text { Intervention, } \mathrm{N}=13 \text {, } \\
\text { Control, } \mathrm{N}=9 \\
\text { Significant Improvement (defined as } 50 \% \text { to } 74 \% \text { reduction on HAMD); Intervention, } \\
\mathrm{N}=21 \text {, } \\
\text { Control, } \mathrm{N}=14 \\
\text { Modest Improvement (defined as } 25 \% \text { to } 49 \% \text { reduction on HAMD) } \\
\text { Intervention, } \mathrm{N}=2 \text {, } \\
\text { Control, } \mathrm{N}=6 \\
\text { Recovery (defined as Remission + Improvement (significant)) } \\
\text { Intervention, data from trial report given as } 89.47 \% \\
\text { Control, data from trial report given as } 60.53 \% \text {, } \\
\text { Chi }{ }^{2}=8.48, \mathrm{P}<0.05\end{array}$} \\
\hline Notes & \multicolumn{2}{|c|}{$\begin{array}{l}\text { Initial data extraction kindly provided by Lufia Chen, with full translation by Dr. Li } \\
\text { Weixiao }\end{array}$} \\
\hline \multicolumn{3}{|l|}{ Risk of bias } \\
\hline Bias & Authors' judgement & Support for judgement \\
\hline $\begin{array}{l}\text { Random sequence generation (selection } \\
\text { bias) }\end{array}$ & Unclear risk & $\begin{array}{l}\text { The authors do not say how randomisation } \\
\text { was achieved. }\end{array}$ \\
\hline Allocation concealment (selection bias) & Unclear risk & $\begin{array}{l}\text { Authors did not adequately report on allo- } \\
\text { cation methods. }\end{array}$ \\
\hline $\begin{array}{l}\text { Blinding of participants and personnel } \\
\text { (performance bias) } \\
\text { All outcomes }\end{array}$ & High risk & $\begin{array}{l}\text { It is not possible to blind participants for } \\
\text { this kind of activity and so this item must } \\
\text { be considered high risk }\end{array}$ \\
\hline $\begin{array}{l}\text { Blinding of outcome assessment (detection } \\
\text { bias) } \\
\text { All outcomes }\end{array}$ & Unclear risk & $\begin{array}{l}\text { No information is given on who conducted } \\
\text { the assessment.. }\end{array}$ \\
\hline $\begin{array}{l}\text { Incomplete outcome data (attrition bias) } \\
\text { All outcomes }\end{array}$ & Low risk & $\begin{array}{l}\text { The authors state that there were no drop- } \\
\text { outs. }\end{array}$ \\
\hline Selective reporting (reporting bias) & Low risk & $\begin{array}{l}\text { The protocol is not available, but all ex- } \\
\text { pected outcomes are reported (Higgins } \\
\text { 2011, Section 8.5.c) }\end{array}$ \\
\hline Other bias & High risk & $\begin{array}{l}\text { A lack of information about treatment fi- } \\
\text { delity combined with a low level of thera- } \\
\text { pist training (nursing plus counselling) }\end{array}$ \\
\hline
\end{tabular}




\begin{tabular}{|c|c|}
\hline Study & Reason for exclusion \\
\hline Akandere 2011 & Population (healthy conservatory students). Also not DMT. \\
\hline Alpert 2007 & Population (healthy older women; no depression). \\
\hline Ando 2009 & Population (cancer patients; depression was one of the symptoms) \\
\hline Anonymous 2007 & Type of study (not R CT). \\
\hline Astin 2003 & Population (Fibromyalgia patients; not depression). \\
\hline Baptista 2012 & Population (fibromyalgia; not depression) . \\
\hline Belcher 2009 & Intervention (yoga; not DMT). \\
\hline Birks 2007 & intervention (salsa; not DMT). \\
\hline Bolton 2009 & Population (children with PTSD; not depression). \\
\hline Brittle 2009 & Intervention (exercise, not DMT). \\
\hline Bräuninger 2012 & Population (Depression was a comorbid diagnosis, but not primary) \\
\hline Carbonell-Baeza 2010 & Population (Fibromyalgia ; not depression). \\
\hline
\end{tabular}

Cross 2012 Intervention (although labell ed dance movement therapy, this was musical dance observation, i.e. no active participation )

Duberg $2013 \quad$ Population (not depression).

Eyigor $2009 \quad$ Population. Healthy individuals were identified; not people with depression. Also intervention was Turkish folklore dance; not DMT

Gordin 1981 Type of study. This was not a RCT. Groups were matched for scores on the State-Trait Anxiety Inventory. The population was also anxious rather than depressed, and none of the groups was DMT (though there was a music group)

Haboush $2006 \quad$ Intervention (ballroom dance).

Hackney $2010 \quad$ Type of study (case study).

Harden 1989 Type of study (quasi-experimental pre-post test design).

Hartshorn $2002 \quad$ Population. Participants were old people in residential homes; not people with depression. Also the measures and changes reported are primarily physical 
(Continued)

\begin{tabular}{|c|c|}
\hline Hautzinger 1995 & $\begin{array}{l}\text { Intervention. Dance is mentioned as one of the comparison groups, but is treated as a sport rather than as } \\
\text { therapy }\end{array}$ \\
\hline Heber 1993 & Type of stud y : case analysis, no control group. \\
\hline Hilf 2009 & Population (somatoform disorders primary). \\
\hline Horrocks 2009 & Type of study: Evaluation methods, not RCT. \\
\hline Kaltsatou 2011 & Population (women with breast cancer; not depression as the primariy diagnosis) \\
\hline Karkou 2010 & Population (adolescents at risk of developing mental health problems; not adolescents with depression) \\
\hline King 2010 & Intervention (dance; not DMT, though investigates aspects of movement used in DMT) \\
\hline Koch 2007 & Intervention (dance not DMT, though investigates aspects of movement used in DMT) \\
\hline Konstantinidou 2005 & Population (participants did not have depression as the primary diagnosis) \\
\hline Krantz 1994 & Population (participants did not have depression as the primary diagnosis) \\
\hline Lauž a 2011 & Type of study (no randomisation). \\
\hline Lopez-Rodriguez 2012 & I nter vention (aquatic biodance) . \\
\hline Lopez-Rodriguez 2013 & Population (fibromyalg ia and a range of psychological outcomes; depression not primary ) \\
\hline Malkina Pykh 2012 & Population (eating disorders). \\
\hline Mannheim 2013 & Popu lation (oncology). \\
\hline Martin 2013 & Population (young people who self-injure). \\
\hline Osteras 2012 & Population ( patie nts with anxiety and depression following meniscus injury, not depression primary ) \\
\hline Payne 2010 & Type of study (a mixed method was applied to a single-case design; not RCT) \\
\hline Pinniger 2012 & Intervention (tango,not DMT). \\
\hline Pinniger 2013a & Population (macular degeneration). \\
\hline Pinniger $2013 \mathrm{~b}$ & Intervention (tango, not DMT). \\
\hline Price 2004 & Population (defined by history of child sexual abuse rather than diagnosis of depression) \\
\hline Rasa 2011 & Type of study (no control). \\
\hline
\end{tabular}


(Continued)

\begin{tabular}{ll}
\hline Reichhart 2010 & Type of study (naturalistic longitudinal design with waiting list control) \\
\hline Reinemann 1998 & Population (learning disabilities). ROM (range of motion) dance is based on Tai Chi \\
\hline Selman 2012 & Type of study: non-randomised. \\
\hline Smith 1998 & Intervention (music; not DMT). \\
\hline Stewart 1994 & Type of study (randomised multiple single case design; not RCT) \\
\hline Stötter 2013 & Intervention (mindfulness based touch therapy). \\
\hline Vanková 2008 & Population (46\% had depression; not clear what the intervention was either) \\
\hline Yang 2009 & Intervention (Body-Mind-Spirit Group Psychotherapy; not DMT) \\
\hline Zemite 2011 & Type of study (no randomisation). \\
\hline
\end{tabular}

\section{Characteristics of ongoing studies [ordered by study ID]}

\section{Joseph 2014}

\begin{tabular}{ll}
\hline $\begin{array}{l}\text { Trial name or title } \\
\text { Methods }\end{array}$ & An investigation into the practice of Dance Movement Psychotherapy with adolescents within UK schools \\
\hline Participants & Adolescents with depression \\
\hline Interventions & Group Dance Movement Psychotherapy \\
\hline Outcomes & Not available \\
\hline Starting date & 2012 \\
\hline Contact information & julie@commonthreadgroup.com \\
\hline Notes & This is a PhD study (director of studies: Dr V. Karkou) \\
\hline
\end{tabular}


DATA AND ANALYSES

Comparison 1. DMT vs standard care or waiting list control

\begin{tabular}{|c|c|c|c|c|}
\hline Outcome or subgroup title & $\begin{array}{l}\text { No. of } \\
\text { studies }\end{array}$ & $\begin{array}{c}\text { No. of } \\
\text { participants }\end{array}$ & Statistical method & Effect size \\
\hline 1 Depression score & 3 & 147 & Std. Mean Difference (IV, Random, 95\% CI) & $-0.67[-1.40,0.05]$ \\
\hline $\begin{array}{l}2 \text { Depression score sub-group } \\
\text { analysis children vs adults }\end{array}$ & 3 & & Mean Difference (IV, Random, 95\% CI) & Subtotals only \\
\hline 2.1 children & 1 & 40 & Mean Difference (IV, Random, 95\% CI) & $0.30[-4.82,5.42]$ \\
\hline 2.2 adults & 2 & 107 & Mean Difference (IV, Random, 95\% CI) & $-7.33[-9.92,-4.73]$ \\
\hline 3 Drop-outs & 1 & 31 & Odds Ratio (IV, Random, 95\% CI) & $1.82[0.35,9.45]$ \\
\hline $\begin{array}{l}4 \text { Social and occupational } \\
\text { functioning }\end{array}$ & 1 & 40 & Mean Difference (IV, Random, 95\% CI) & $-6.80[-11.44,-2.16]$ \\
\hline 5 Quality of life & 1 & 22 & Mean Difference (IV, Random, 95\% CI) & $0.30[-0.60,1.20]$ \\
\hline 6 Self-esteem & 1 & 21 & Mean Difference (IV, Random, 95\% CI) & $1.70[-2.36,5.76]$ \\
\hline
\end{tabular}

\section{Analysis I.I. Comparison I DMT vs standard care or waiting list control, Outcome I Depression score.}

Review: Dance movement therapy for depression

Comparison: I DMT vs standard care or waiting list control

Outcome: I Depression score

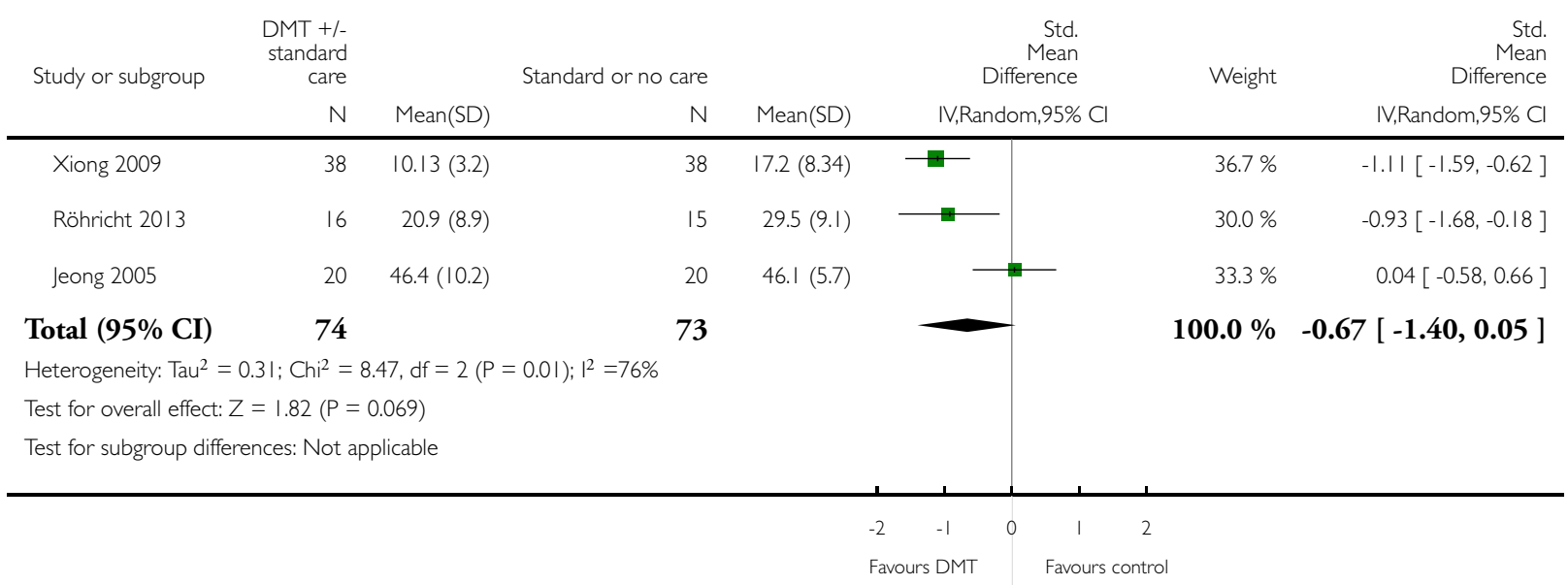

Dance movement therapy for depression (Review)

Copyright @ 2015 The Cochrane Collaboration. Published by John Wiley \& Sons, Ltd. 
Analysis I.2. Comparison I DMT vs standard care or waiting list control, Outcome 2 Depression score subgroup analysis children vs adults.

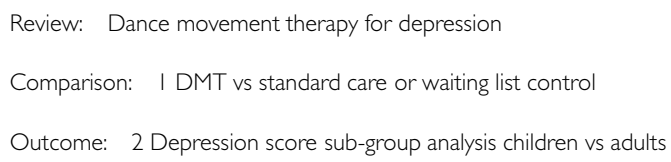

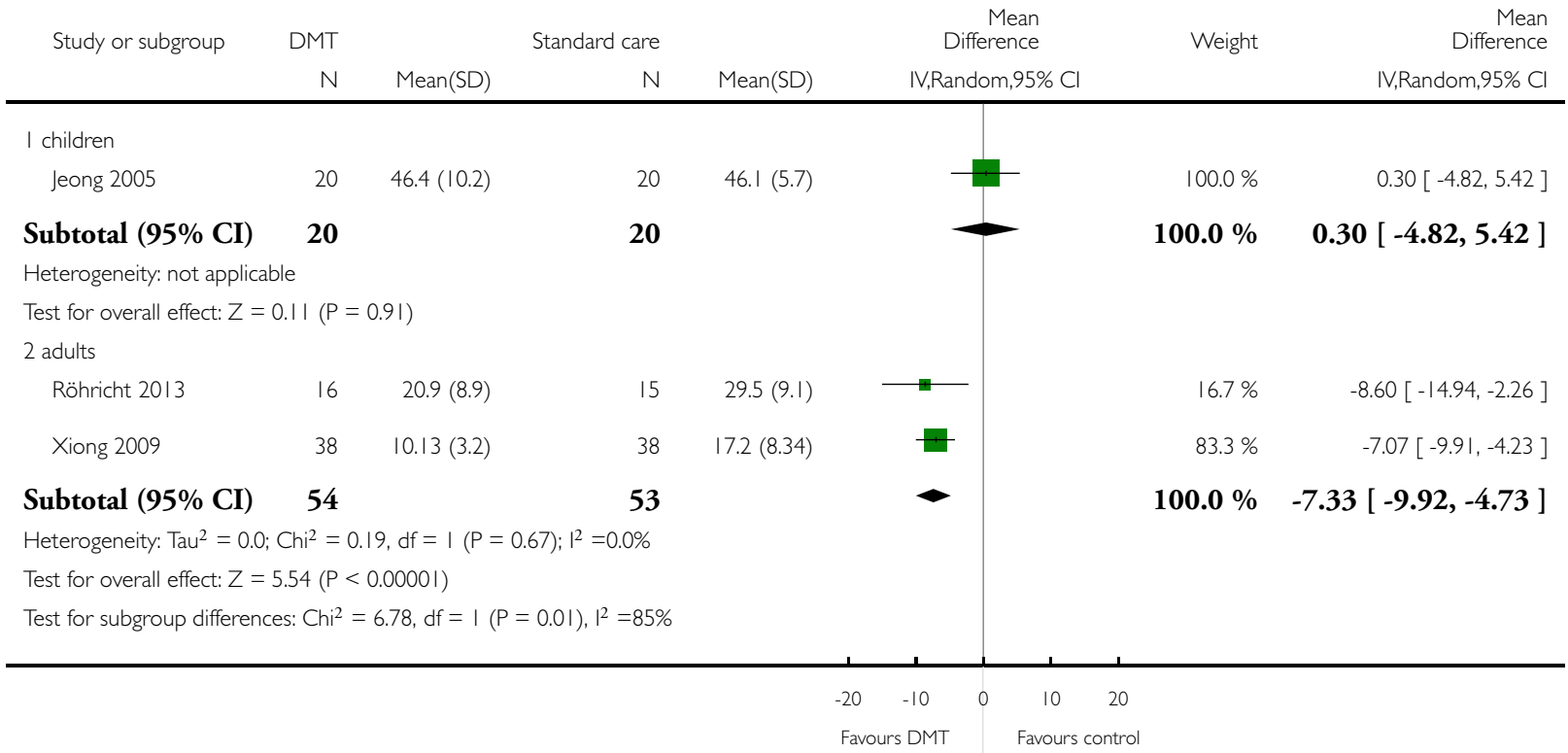




\section{Analysis I.3. Comparison I DMT vs standard care or waiting list control, Outcome 3 Drop-outs.}

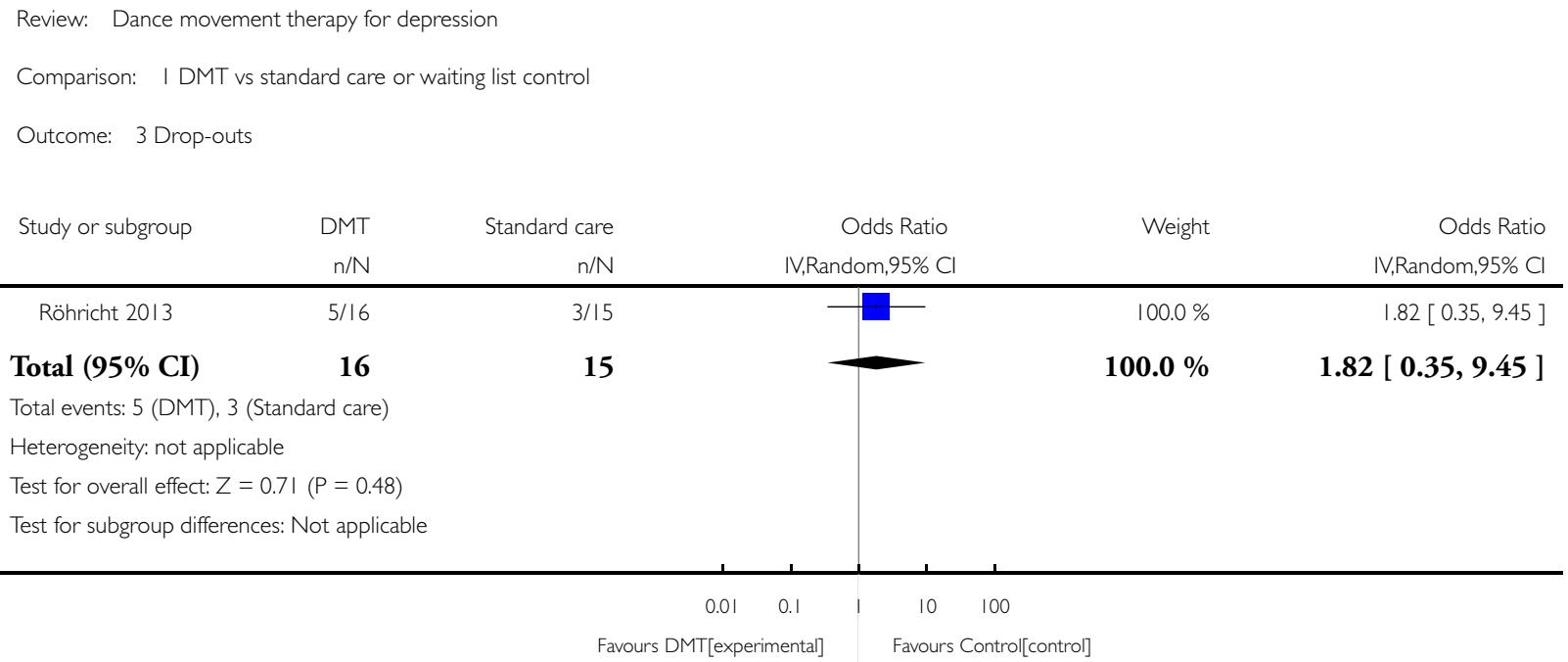

\section{Analysis I.4. Comparison I DMT vs standard care or waiting list control, Outcome 4 Social and occupational functioning.}

Review: Dance movement therapy for depression

Comparison: I DMT vs standard care or waiting list control

Outcome: 4 Social and occupational functioning

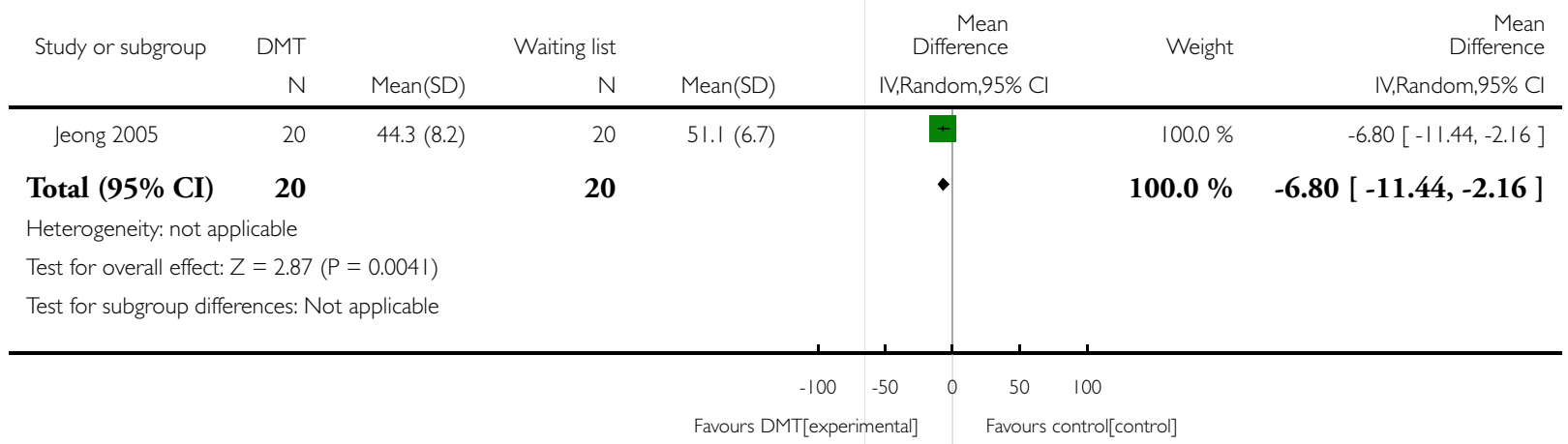


Analysis I.5. Comparison I DMT vs standard care or waiting list control, Outcome 5 Quality of life.

Review: Dance movement therapy for depression

Comparison: I DMT vs standard care or waiting list control

Outcome: 5 Quality of life

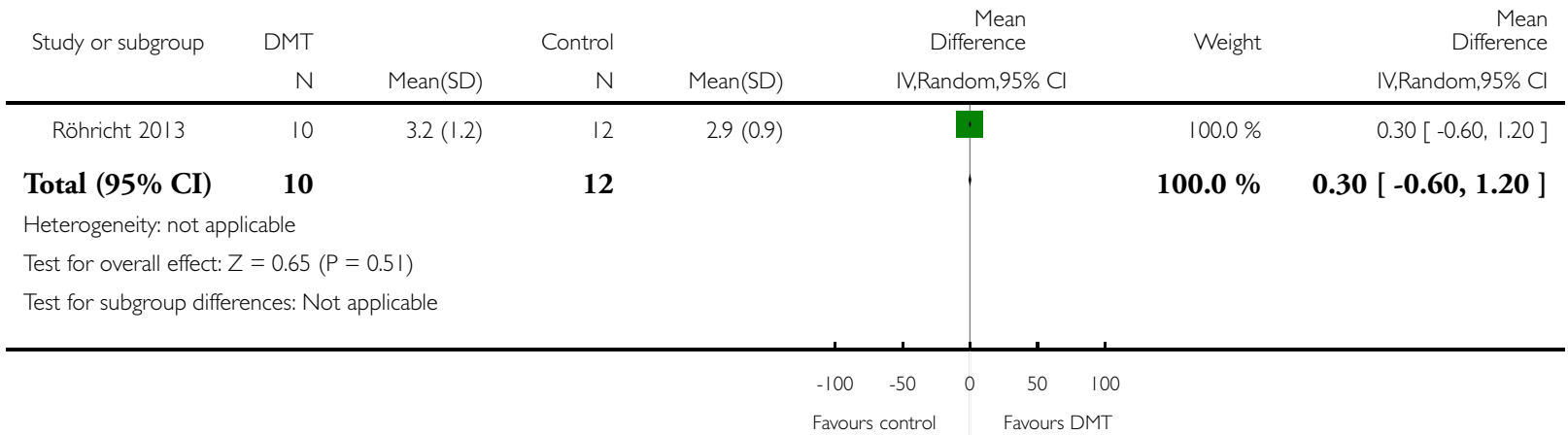

Analysis I.6. Comparison I DMT vs standard care or waiting list control, Outcome 6 Self-esteem.

Review: Dance movement therapy for depression

Comparison: I DMT vs standard care or waiting list control

Outcome: 6 Self-esteem

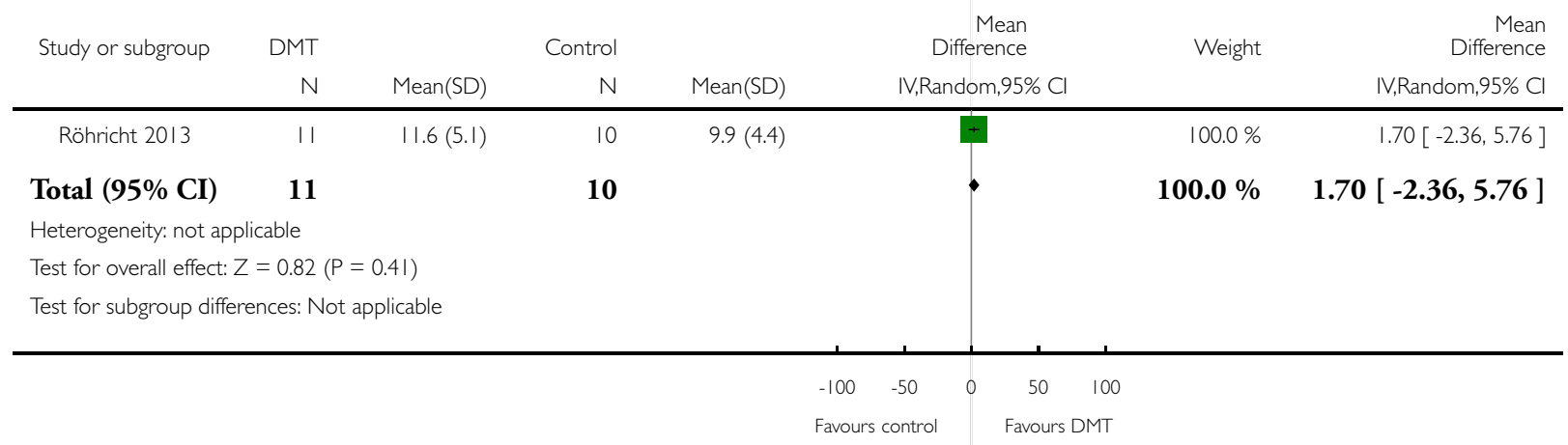




\section{A P P E N D I C E S}

\section{Appendix I. Search strategy for AMED, CINAHL, ERIC and Dissertation abstracts}

1. CCDANCTR (Studies and References Register) (all years to 2nd October 2014)

Searh terms used:

((depress* or dysthymi* or "adjustment disorder"” or "mood disorder*" or "affective disorder*" or "affective symptom*") AND (danc* or "authentic movement*" or "movement therap"” or "movement psychotherap" or "body psychot*”)):ti,ab,kw,ky,emt,mh,mc

Key: ab:abstract; ti:title; kw:keywords; ky:other keywords; emt:EMTREE headings; mh: MeSH headings; mc:MeSH checkwords; so:sourcel journal name

2. CINAHL (all years to 2nd October 2014)

Searh terms used:

S1 (MH "Dance Therapy")

S2 (dance N3 (therap* or psychotherap*))

$\mathrm{S} 3$ (S1 or S2)

S4 (MH "Depression+")

S5 depress*

S6 (S4 or $\mathrm{S} 5)$

S7 (S3 and S6)

3. AMED, ERIC and Dissertation Abstracts

Searches were initially carried out in 2012 using the CCDANCTR search terms as listed above, however this search strategy generated a lot of 'noise', especially for the Dissertation Abstracts.

When update searches were carried out (02-Aug-2013) new search terms were used for dissertation abstracts, in order to reduce the number of irrelevant studies:

(dance PRE/1 therapy NEAR depression AND random* NEAR controlled)

No further studies were found through any of the August 2013 searches.

\section{Appendix 2. Standard letter sent to professional associations, educational programmes and experts in the field}

Standard e-mail

Dear colleague,

We are authors of the Cochrane Systematic Review: Dance Movement Therapy for Depression. The outcome of this review is expected to have an impact on policy documents, governmental guidelines, services and potentially employment.

As part of our review strategy, we would like to invite colleagues to let us know of any trials of Dance Movement Therapy for depression. A trial is a research study of two groups, one receiving Dance Movement Therapy and one 'control', that is either receiving some other kind of intervention or none at all. Participants will all have measured symptoms of depression.

We wish to locate all relevant studies, whether published or unpublished, small or large scale, attached to an institution or independent. We are also interested in any conference proceedings you know of that might include Dance Movement Therapy research. If in doubt, do let us know of your work, and please also let us know of anyone else you think may have conducted such a study. It is better that we hear about the same study several times over than miss it.

Please send full references or copies of your studies in pdfs or word documents to either Dr Bonnie Meekums at b.meekums@leeds.ac.uk or DrVicky Karkou at vkarkou@qmu.ac.uk.

We look forward to receiving information from you. Thank you in advance for your co-operation with us and for passing this e-mail to people who have been or are currently involved in Dance Movement Therapy research, your professional associations and any other relevant networks.

Best wishes,

Dr Bonnie Meekums, University of Leeds, UK

and

Dr Vicky Karkou, Queen Margaret University, Edinburgh, UK

On behalf of the Review Team

Dance movement therapy for depression (Review) 


\section{Appendix 3. Sample of data extraction form}

\section{Data Extraction for all Relevant Studies}

General information

- 'Data extractor'/author ID:

- Date of extraction:

- Study ID:

- Title, author/s, publication details of study:

- Source if unpublished:

- language of publication:

\section{Eligibility criteria}

Does the study meet the inclusion criteria, and how?

- Study design (parallel, controlled trial, randomised controlled trial):

- Participants (diagnosis of depression, valid and reliable depression scores or symptom measures):

- Interventions (type of dance movement therapy):

- Outcomes (changes in scores of depression and depressive symptoms:

Inclusion? $\quad$ Exclusion? More Information Needed ?

Data Extraction for Included Studies

Study characteristics

- Study setting (e.g. country, urban/rural, hospital/clinic/school/charity/community/prison etc:

- Participant demographics (e.g. age, gender, socio-economic status, co-morbidity):

- Inclusion/exclusion criteria used in the study:

\section{Outcome measures used in the study}

- Primary outcome measures that provide scores for:

1. Depression as measured using valid and reliable scale measurements

1. Depressive symptoms including: low mood; fatigue; sleep disturbance; appetite disturbance; suicidal ideation

- Secondary outcome measures that provide scores for:

1. Social and occupational functioning, (e.g. engagement in social activities)

1. Quality of life

1. Self esteem and body image

Dance movement therapy for depression (Review)

Copyright $\odot 2015$ The Cochrane Collaboration. Published by John Wiley \& Sons, Ltd. 
1. Adverse effects (including injury, suicide or suicide attempt/s)

1. Overall treatment dropouts

1. Costs

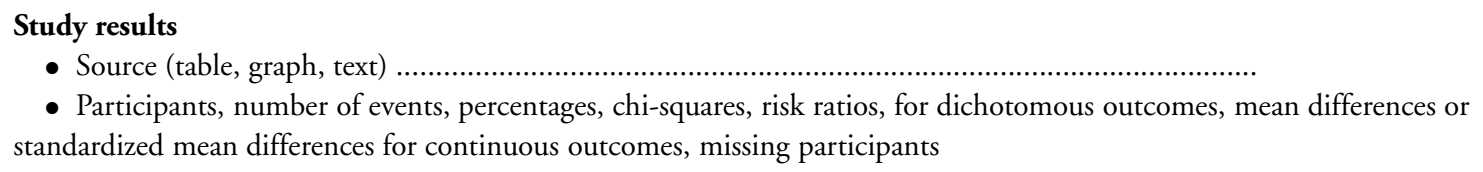

- Queries regarding data or methods (to be referred to the author for further information)

Additional notes

- Record of details regarding correspondence with author/s for additional information or clarification of queries

- Ethics of stated conflict of interest

- Details of other studies cited in the references

- Duplicate publications

- Translation required

Risk of bias assessment

1. Selection bias

a) Method of randomisation

Was the trial reported as randomised?

Was the method of randomisation appropriate?

\section{YES/NO/UNCLEAR \\ YES/NO/UNCLEAR}

Randomization will be rated as appropriate if every participant had equal chance to be selected for either condition and if investigator was unable to predict which treatment the participant would be assigned to. Examples are: random number table; computer random number generator; coin tossing; shuffling cards or envelopes; throwing dice; drawing lots; minimization.

Inappropriate methods include: use of date of birth; sequence generated by a rule e.g. date of admission; patient preference; clinician judgement; availability of the intervention.

Unclear: insufficient information on which to base judgement.

\section{b) Allocation concealment}

Was allocation concealment adequate?

\section{YES/NO/UNCLEAR}

Adequate - methods to conceal allocation include: central allocation (e.g. telephone, web or pharmacy based randomisation); serially numbered, opaque, sealed envelopes; other descriptions with convincing concealment

Inadequate methods include: open random allocation schedule, e.g. list of random numbers; envelopes without safeguards, e.g. unsealed, non-opaque or not sequentially numbered; alternation or rotation; date of birth; case record number; any other explicitly unconcealed procedure.

Unclear: authors did not adequately report on method of concealment

2. Blinding of participants and personnel

Was the discussion of participant and personnel blinding adequate?

\section{YES/NO/UNCLEAR}

NB For dance movement therapy studies, it is not possible to blind participants and those providing the dance movement therapy interventions. Adequate discussion of blinding would therefore be implied in adequate randomisation and allocation concealment (see above).

Dance movement therapy for depression (Review) 
Inadequate blinding would be implied in studies for example in which the therapist, participant and/or researcher chooses participants for the experimental group.

Unclear blinding would be implied in cases in which either allocation concealment or randomisation are unclear.

\section{Blinding of outcome assessment}

Was discussion of blinding of outcome assessment adequate? YES/NO/UNCLEAR

NB A yes is possible if blinding of outcome assessment is not ensured (both blinded and unlikely to be broken), but that the review authors judge this is unlikely to influence outcome measurement.

A judgement of unclear will be used if the study does not address this.

4. Dealing with missing data

Was missing data adequately reported?

YES/NO/UNCLEAR

Dealing with missing data will be considered adequate when: there are no missing outcome data; reasons for missing data unlikely to be related to true outcome; missing outcome data are balanced across comparison groups, with similar reasons; plausible effect size (difference in means or standardized difference in means) among missing outcomes is insufficient to have clinically relevant impact on observed effect size; missing data are imputed using appropriate methods (e.g. an intention to treat (ITT) analysis for continuous data). Inadequate: reasons for missing outcome data likely to be related to true outcome, with either imbalance of numbers or reasons for missing data across groups; plausible effect size among missing outcomes sufficient to induce clinically relevant bias in observed effect size; 'as treated' analysis performed with substantial departure of the intervention received from that assigned at randomisation; potentially inappropriate application of simple imputation.

Unclear: insufficient reporting of attrition or exclusions to permit judgement, e.g. number randomisation not stated or no reasons for missing data given; or the study did not address this outcome.

\section{Outcome reporting bias}

Was the reporting bias acceptable?

YES/NO/UNCLEAR

Reporting bias will be assessed as acceptable if: the study protocol is available and all pre-specified outcomes of interest in the review have been reported in the pre-specified way; or the protocol is not available but it is clear that the published reports include all expected outcomes.

Unacceptable: not all of the pre-specified primary outcomes are reported; one or more of these is reported using measurements or analytic methods or subsets of data that were not pre-specified; one or more of the primary outcomes were not pre-specified (unless clearly justified, e.g. adverse effect); one of more outcome of interest is reported incompletely and so cannot be entered into metaanalysis; failure to report results for a key outcome that would be expected from such a study (including adverse outcomes).

Unclear: insufficient information to make a judgement.

\section{Other sources of bias}

Were other sources of bias eliminated: YES/NO/UNCLEAR

Examples of other risk of bias include: those related to study design; claimed to be fraudulent.

Examples of unclear risk of bias include: insufficient rationale or evidence that an identified problem would introduce bias.

The above criteria will be used to give each article an overall methodological quality rating, as follows:

A. Low risk of bias - all criteria met.

B. Moderate risk of bias - one or more of the criteria only partly met.

C. High risk of bias - one or more criteria not met.

Studies will not be excluded based on a low methodological quality score.

\section{CONTRIBUTIONSOFAUTHORS}

Draft the protocol: BM, VK and AN. Develop search strategy and undertake searches: VK and BM in consultation with the CCDAN Trials Search Co-ordinator. Data extraction and management: BM and VK. Assessment of quality: BM, VK and AN. Analysis and synthesis: statistical, AN and BM; narrative, BM and VK.

Dance movement therapy for depression (Review) 


\section{DECLARATIONSOF INTEREST}

Both Karkou and Meekums are members of the Association for Dance Movement Psychotherapy UK (ADMP, UK). Both have completed studies that may be included in the review.

\section{SOURCES OF SUPPORT}

\section{Internal sources}

- University of Leeds, School of Healthcare, UK.

Provided computer/email resources and time for Meekums and Nelson to work on review, as well as some pump prime monies which funded face-to-face meetings.

- Queen Margaret University, School of Health Sciences, UK.

Provided computer/email resources and time for Karkou to work on review. Offered access to electronic databases for Mala to work on scoping review

- Edge Hill University, UK.

Provided time and resources for Karkou to work on writing up the review.

\section{External sources}

- Lufia Chen, Other.

Partial translation of Xiong 2009

- Dr. Li Weixiao, China.

Full translation of Xiong 2009

\section{DIFFERENCES BETWEEN PROTOCOLANDREVIEW}

Any differences between the protocol and the review are as a result of the number of studies available and therefore the options for subgroup analyses and sensitivity analyses.

\section{NDEX TERMS}

\section{Medical Subject Headings (MeSH)}

*Movement; Antidepressive Agents [therapeutic use]; Dance Therapy [ ${ }^{*}$ methods]; Depression [*therapy]; Empathy; Psychotherapy; Randomized Controlled Trials as Topic; Sensation

\section{MeSH check words}

Adolescent; Adult; Female; Humans; Male 